\title{
1 A non-transcriptional function of Yap orchestrates the DNA 2 replication program
}

3

Rodrigo Meléndez García $^{1 \dagger}$, Olivier Haccard ${ }^{2 \dagger}$, Albert Chesneau ${ }^{1}$, Hemalatha Narassimprakash $^{2}$, Jérôme E Roger ${ }^{1}$, Muriel Perron ${ }^{1 *}$, Kathrin Marheineke ${ }^{2 *}$ and Odile Bronchain $^{1 *}$

${ }^{1}$ Paris-Saclay Institute of Neuroscience, CNRS, Université Paris-Saclay, CERTO-Retina France, 91400 Saclay, France

${ }^{2}$ Université Paris-Saclay, CEA, CNRS, Institute for Integrative Biology of the Cell (I2BC), 91198 Gif-sur-Yvette, France

$\dagger$ These authors contributed equally to this work

* These authors are co-last authors and contributed equally

\section{Key words:}

Hippo/Yap pathway, Rif1, DNA replication, retinal stem cells, Xenopus

\section{Highlights:}

- Yap is recruited to chromatin during DNA replication dependent on pre-replicative complex assembly.

- Yap controls DNA replication dynamics by limiting origin firing.

- The replication timing regulatory factor 1, Rif1, is a novel Yap binding-partner.

- Both Yap and Rif1 regulate the length of the first embryonic cell cycles.

- Like Yap, Rif1 controls retinal stem cell DNA replication timing. 


\section{Abstract}

2

In multicellular eukaryotic organisms, the initiation of DNA replication occurs asynchronously throughout S-phase according to a regulated replication timing program. Here, using Xenopus egg extracts, we showed that Yap (Yes-associated protein 1), a downstream effector of the Hippo signaling pathway, is required for the control of DNA replication dynamics. We found that Yap is recruited to chromatin at the start of DNA replication and that Yap depletion accelerates DNA replication dynamics by increasing the number of activated replication origins. Furthermore, we identified Rifl, a major regulator of the DNA replication timing program, as a novel Yap binding protein. In Xenopus embryos, using a Trim-Away approach during cleavage stages devoid of transcription, we found that both Yap and Rifl depletion trigger an acceleration of cell divisions, suggesting a shorter S-phase by alterations of the replication program. Finally, our data show that Rif1 knockdown leads to defects in the partitioning of early versus late replication foci in retinal stem cells, as we previously showed for Yap. Altogether, our findings unveil a non-transcriptional role for Yap in regulating replication dynamics. We propose that Yap and Rifl function as breaks to control the DNA replication program in early embryos and post-embryonic stem cells. 


\section{Introduction}

Prior to cell division, DNA must be entirely and accurately duplicated to be transmitted to the daughter cells (Fragkos et al., 2015). In metazoan cells, DNA replication initiates at several thousands of fairly specific sites called replication origins in a highly-orchestrated manner in time and space (Machida et al., 2005; Prioleau and MacAlpine, 2016). In late mitosis and G1 phase, origins are first "licensed" for replication by loading onto chromatin the six ORC (origin recognition complex) subunits, then Cdc6 (cell-division-cycle 6) and Cdt1 (chromatin licensing and DNA replication factor 1), and finally the MCM (mini-chromosome maintenance) 2-7 helicase complex, forming the pre-replicative complex (pre-RC, for review see (Bell and Kaguni, 2013)). Pre-RC is subsequently activated during S-phase by cyclin- and Dbf4/Drf1dependent kinases (CDKs and DDKs) which leads to the recruitment of many other factors, DNA unwinding and start of DNA synthesis at origins. In eukaryotes, segments of chromosomes replicate in a timely organized manner throughout S-phase. It is now widely accepted that the genome is partitioned into different types of genomic regions of coordinated activation (Marchal et al., 2019). During the first half of S-phase, the early-replicating chromatin, mainly transcriptionally active and localized to central regions of the nucleus, duplicates while late replicating chromatin, spatially located at the periphery of the nucleus, awaits until the second half (Berezney et al., 2000; Hiratani et al., 2010; Ryba et al., 2010). This pattern of DNA replication, also called DNA replication timing (RT) program, has been found to be stable, somatically heritable, cell-type specific, and associated to a cellular phenotype. As such, the RT can be considered as an epigenetic mark (Hiratani and Gilbert, 2009) and provides a specific cell state signature. Interestingly, a defined RT has been observed at very early stages in development, prior to the mid-blastula transition (MBT), in embryonic cells (also called blastomeres) undergoing rapid cell cycle consisting of only S/M phases that are typical of animals with external development (Siefert et al., 2017). Due to the absence of most transcriptional activities in these early embryos (Newport and Kirschner, 1982), the very rapid DNA synthesis during these cleavage divisions relies only on a stockpile of maternally supplied determinants. To date, little is known about the molecular cues that ensure faithful and complete DNA replication during early embryonic cell divisions.

Very few gene knockouts have been shown to trigger alterations in the RT (Dileep et al., 2015; Marchal et al., 2019). Until now, the replication timing regulatory factor 1, Rif1, is one of the very few trans-acting factors whose loss of function has been found to result in major RT modifications in multicellular organisms (Cornacchia et al., 2012; Yamazaki et al., 2012). Rif1 inhibits the firing of late origins by targeting PP1 (Protein Phosphatase 1) to those origins, counteracting Cdc7/Dbf4 dependent Mcm4 phosphorylation in budding yeast and Xenopus egg extracts (Alver et al., 2017; Davé et al., 2014; Hiraga et al., 2014). We previously identified Yap as another factor implicated in RT control (Cabochette et al., 2015). Yap is a downstream effector of the Hippo signaling pathway. It was initially identified as a primary regulator of organ growth due to its action on embryonic progenitor cells (Huang et al., 2005; Lian et al., 2010; Ramos and Camargo, 2012; Zhao et al., 2010). Yap is mostly known to exert its function as a transcriptional co-activator acting via binding to the TEADs (transcriptional enhanced associated domain transcription factors) to control transcriptional programs involved in cell proliferation, differentiation, survival and migration (Totaro et al., 2018; Zhao et al., 2008). We previously found that yap is specifically expressed in neural stem cells in the Xenopus retina and that its knockdown in these cells leads to altered RT associated with a dramatic S-phase shortening (Cabochette et al., 2015). However, whether Yap is directly involved in DNA replication dynamics and whether it could regulate DNA replication during early embryonic divisions in the absence of transcription remained to be investigated. 
1 We first addressed this question by taking advantage of Xenopus egg extracts, a cell-free system 2 that faithfully recapitulates all steps of DNA replication (Blow and Laskey, 2016, 1986). We 3 and others previously found that in this system activated replication origins are spaced 5 to 15 $4 \mathrm{~kb}$ apart and clustered in early- and late-firing groups of origins (Blow et al., 2001; Herrick et 5 al., 2000; Marheineke and Hyrien, 2004). Here, we found that Yap is recruited onto chromatin 6 at the onset of DNA replication in Xenopus egg extracts in a manner that is dependent on the 7 pre-RC formation. Yap depletion altered replication dynamics by increasing the number of 8 activated origins. We further showed that Yap and Rif1 co-immunoprecipitated. As previously 9 shown in vivo for yap (Cabochette et al., 2015), we found that rifl is expressed in retinal stem 10 and early progenitor cells and involved in their RT signature. Finally, targeted protein depletion 11 at early stages of embryonic development using a Trim-Away strategy, revealed the crucial role 12 of both Yap and Rif1 in controlling the speed of cell divisions before MBT in vivo. Altogether, 13 our findings unveiled Yap implication in the regulation of replication origin activation and 14 identified Rif1 as a novel partner. We propose that Yap, like Rif1, acts as a brake during 15 replication, to control the overall rate of DNA synthesis in early embryos and post-embryonic 16 retinal stem cells. 


\section{Results}

\section{Yap is recruited to chromatin in a pre-RC-dependent manner in Xenopus egg extracts}

Since Yap was described as a co-transcriptional factor, we wondered whether Yap was present in Xenopus egg extracts that are almost devoid of transcriptional activity (Wang and Shechter, 2016). By quantitative western blot, we found that Yap protein is present in S-phase egg extracts at a concentration of $11 \mathrm{ng} / \mu \mathrm{l}(169 \mathrm{nM}$, Figure 1 - figure supplement 1$)$. We therefore further investigated the role of Yap during S-phase in this well characterized in vitro replication system where upon addition of sperm DNA to egg extracts, chromatin is assembled, replication proteins are imported, recruited on chromatin and nuclei synchronously start DNA replication. Thus, this in vitro system mimics the first embryonic S-phase. To know whether Yap interacts with chromatin during S-phase, we incubated sperm nuclei in egg extracts and collected purified chromatin fractions starting from pre-RC assembly up to ongoing DNA replication. This analysis revealed that Yap recruitment onto chromatin coincided with the loading of PCNA, an indicator of the recruitment of DNA polymerases and the start of DNA synthesis (Figure 1A). Yap further accumulated on chromatin following the progression of S-phase. Our results also showed that Yap is recruited to chromatin after the recruitment of the MCM complex (Mcm2, Mcm7) in the Xenopus in vitro system (Figure 1A). To address whether the recruitment of Yap could be dependent on pre-RC assembly on chromatin, we added to the egg extracts recombinant geminin, an inhibitor of Cdt1 necessary for MCM loading (McGarry and Kirschner, 1998; Tada et al., 2001). As a result, the recruitment of Yap on chromatin was severely delayed (Figure 1A, B). Thus, Yap is recruited to chromatin at the start of DNA replication and its recruitment is dependent on functional pre-RC assembly in the Xenopus egg extract system.

\section{Yap depletion triggers the acceleration of DNA synthesis in egg extracts}

To directly assess the role of Yap in DNA replication, we performed immunodepletion experiments. We were able to efficiently remove Yap from egg extracts (Figure 1C). We then used those Yap-depleted ( $\Delta$ Yap) or mock-depleted ( $\Delta$ Mock) egg extracts to monitor nascent strand DNA synthesis after incubating sperm nuclei in the presence of ${ }^{32} \mathrm{P}$-dCTP (Figure $1 \mathrm{D}$ ). Replication reactions were stopped at indicated times during S-phase and quantified (Figure $1 \mathrm{E})$. We found that Yap depletion increased DNA synthesis during the early stages of DNA replication (30-60 min: low molecular weight nascent strands) and to a lesser extent at later stages (75-150 min: high molecular weight strands). We calculated the ratio between Yap- and Mock-depleted maximal incorporation at four different intervals of percentages of incorporation, reflecting early (0-25\% max. incorporation), mid (26-50\%), late (51-75\%) and very late (76-100\%) S-phase. We found that Yap depletion increased on average DNA synthesis 1.8-fold during early S-phase, 1.7-fold during mid S-phase, 1.6-fold during late S-phase and 1.2-fold during very late S-phase. The increase in DNA replication after Yap depletion could be due to a quicker entry into S-phase, because of a more rapid chromatin assembly, rather than an effect on DNA replication itself. We however ruled out this hypothesis by analyzing nascent strands during very early S-phase, which did not reveal any precocious start of DNA synthesis after Yap depletion (Figure 1 - figure supplement 2). Of note, the effect of the Yap depletion was not rescued by adding back the recombinant protein (Figure 1 - figure supplement 3 ). Since Yap localization and function can be modified by many different post-translational modifications (PTMs) (Yan et al., 2020), one cannot exclude that one or more PTMs of the recombinant Yap produced in baculovirus-infected insect cells were missing. Altogether, we found that Yap depletion leads to accelerated DNA synthesis, mainly during the early to midstages of S-phase, suggesting that Yap negatively regulates the progression of DNA replication. 

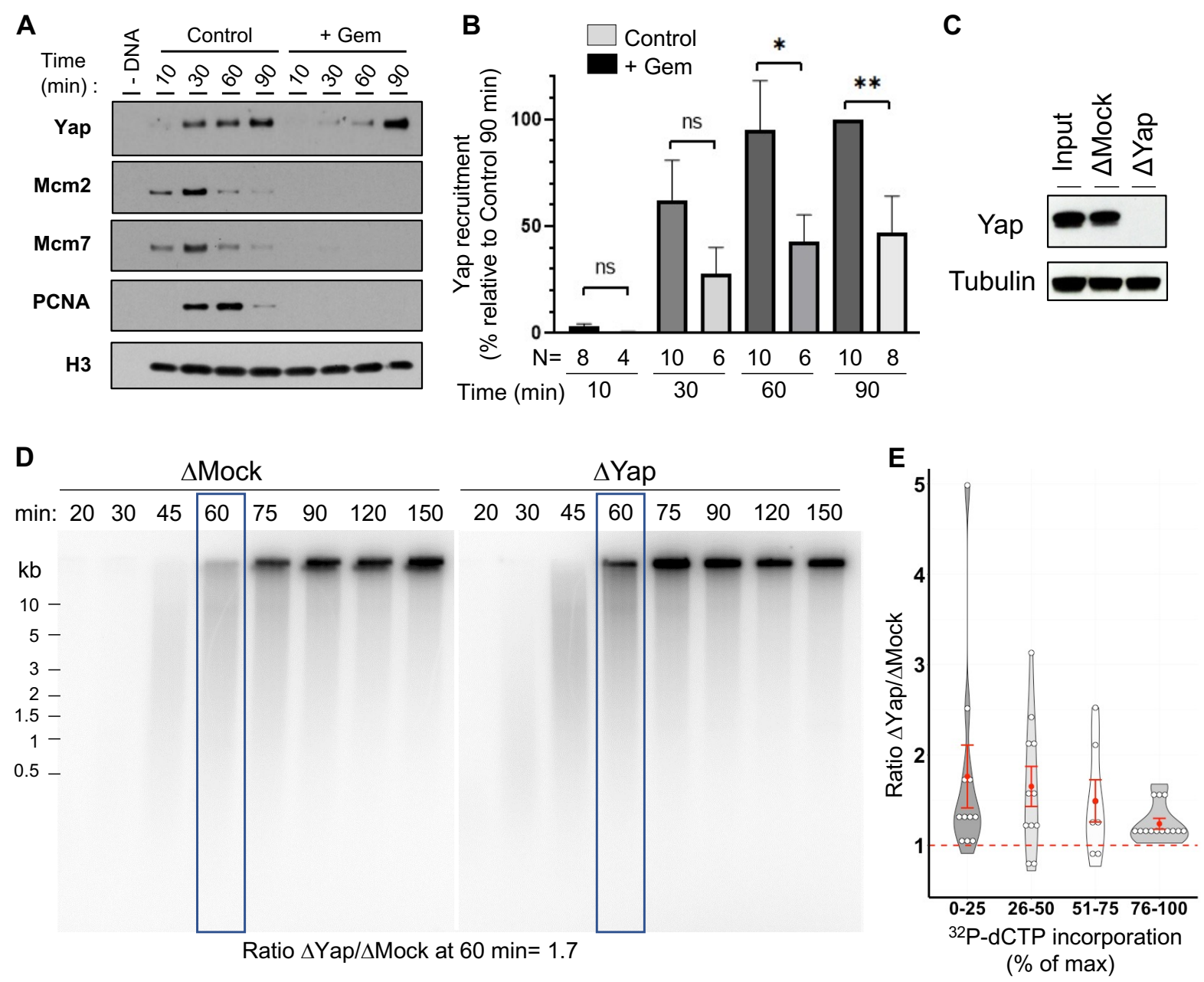

Figure 1. Yap is recruited to chromatin during DNA replication and the absence of Yap accelerates DNA synthesis in Xenopus egg extracts. (A) Sperm nuclei were incubated in Xenopus egg extracts in the absence (Control) or presence of geminin (+ Gem). Chromatin was isolated for immunoblotting at indicated times points before and during DNA replication. (B) Quantification of the amount of Yap: percentage of quantified optical densities of the Yap bands relative to that in the control condition at 90 minutes in isolated chromatin fractions. The number of analyzed fractions per time point during DNA replication is indicated in each bar $(\mathrm{N}=)$. ${ }^{* *} \mathrm{p}=0.0013 ; * \mathrm{p}=0.0225$; ns, not significant. Data is reported as mean \pm SEM. (C) Western blot showing the efficiency of Yap protein depletion in Xenopus egg extracts. Extracts were immunodepleted with either a rabbit anti-Yap antibody ( $\Delta$ Yap) or a random rabbit IgG as a control ( $\Delta$ Mock). Tubulin is used as a loading control. (D) Immunodepleted extracts were supplemented with sperm nuclei and incubated with $\left[\alpha^{32} \mathrm{P}\right] \mathrm{dCTP}$ for different times in order to label nascent DNA during replication. Nascent DNA strands synthesized were analyzed by alkaline gel electrophoresis. The level of radioactivity incorporation was quantified as $\%$ of maximal incorporation for each lane and the ratio of these values in $\Delta$ Yap over $\Delta$ Mock conditions was calculated for each time point. The ratio at 60 minutes is indicated as an example. (E) Violin plot showing $\Delta$ Yap/ $\Delta$ Mock ratios from 8 independent experiments including the one depicted in (D). The time scale was fractionated in 4 periods to distinguish early, mid, late and very late phases of the replication process. The red dashed line highlights a $\Delta$ Yap/ $\Delta$ Mock ratio of 1 that indicates no difference in the level of DNA synthesis between the 2 conditions, with the red dot indicating the mean and the red error bar the SEM, Wilcoxon signed ranked test, $p$-values: $p=0.002(0-25 \%, n=10), p=0.014(26-50 \%, n=11), p=0.16(51$ $75 \%, n=6), p=0.0002(76-100 \%, n=13)$. 


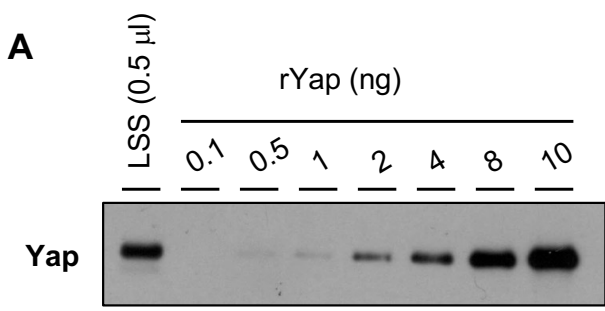

C

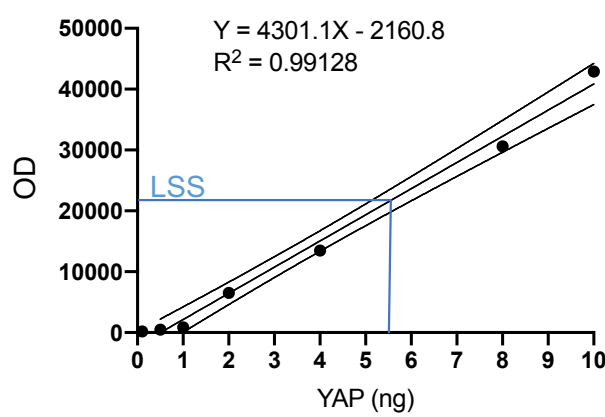

B

\begin{tabular}{|c|r|}
\hline $\mathbf{n g}$ & \multicolumn{1}{c|}{ OD } \\
\hline 0.1 & 182.607 \\
\hline 0.5 & 498.021 \\
\hline 1 & 862.335 \\
\hline 2 & 6508.388 \\
\hline 4 & 13461.016 \\
\hline 8 & 30592.543 \\
\hline 10 & 42877.291 \\
\hline LSS & 21795.836 \\
\hline
\end{tabular}

[Yap]: $5.5 \mathrm{ng}$ in $0.5 \mu \mathrm{l}$ of LSS

\section{Figure 1 - figure supplement 1. Yap protein concentration in Xenopus egg extracts. (A)}

3 Western blot showing different amounts of recombinant Yap (rYap) used to estimate endogenous Yap in egg extracts (low-speed supernatant, LSS). (B, C) The optical densities (OD) of the protein bands from (A) were used to plot a standard curve and to calculate Yap amount in the LSS.

A

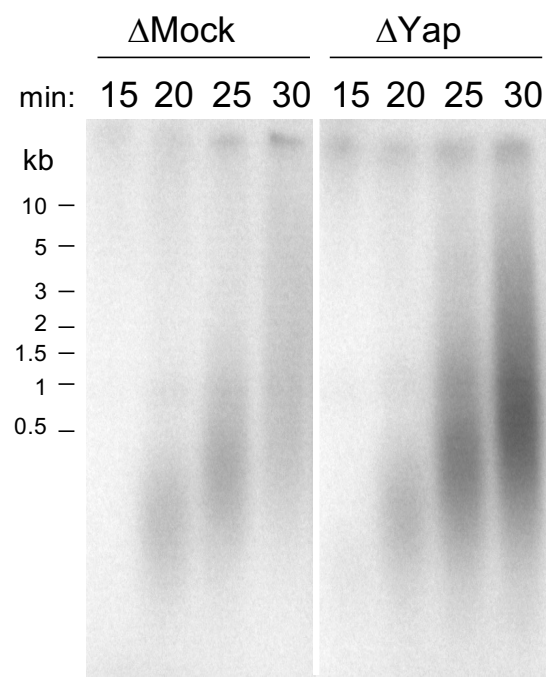

C

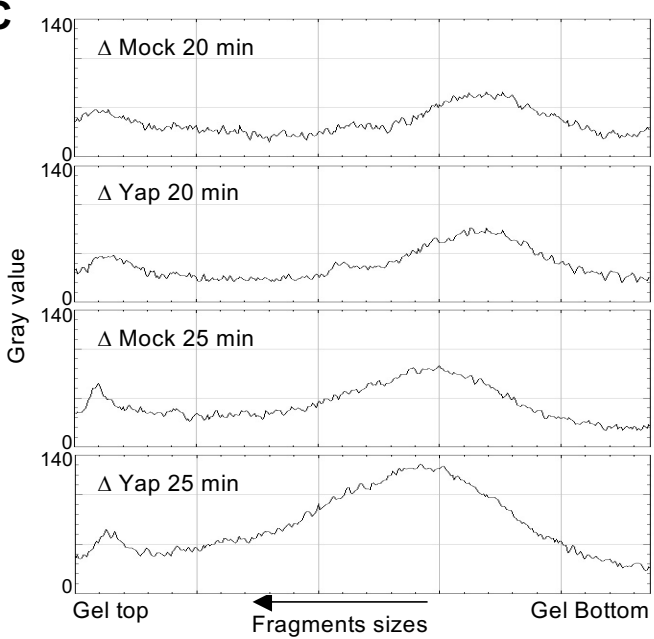

B

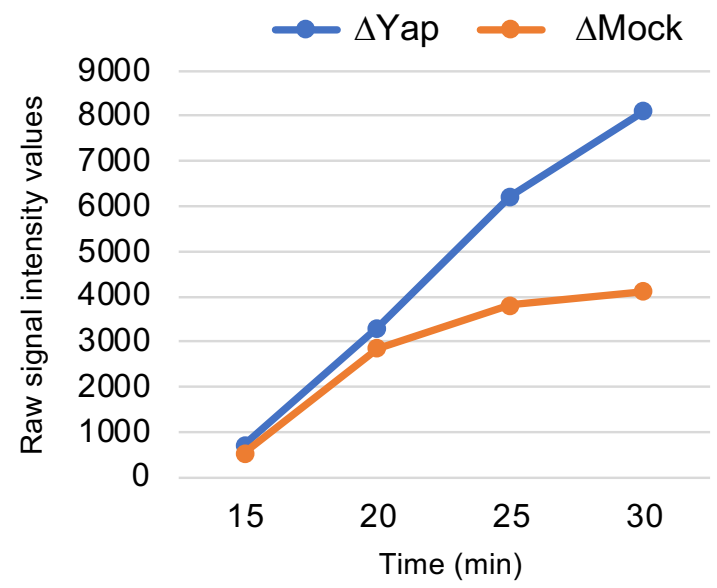


Figure 1 - figure supplement 2. Yap depletion does not affect entry into S-phase. (A) Nascent DNA strands synthesized during early S-phase were analyzed at the indicated times by alkaline gel electrophoresis. (B) The amount of radioactivity incorporation was quantified for each lane and plotted as raw intensity values. Very similar incorporation is observed at the earliest time points (15-20 $\mathrm{min})$ before getting higher in Yap depleted ( $\Delta$ Yap) compared to control depleted extracts ( $\Delta$ Mock) (25-30 min). (C) Grey scale profile (ImageJ) of lanes at 20 and $25 \mathrm{~min}$, showing that size distribution of nascent strands is nearly identical in both

A

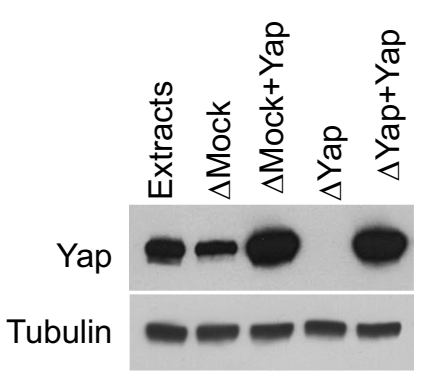

C
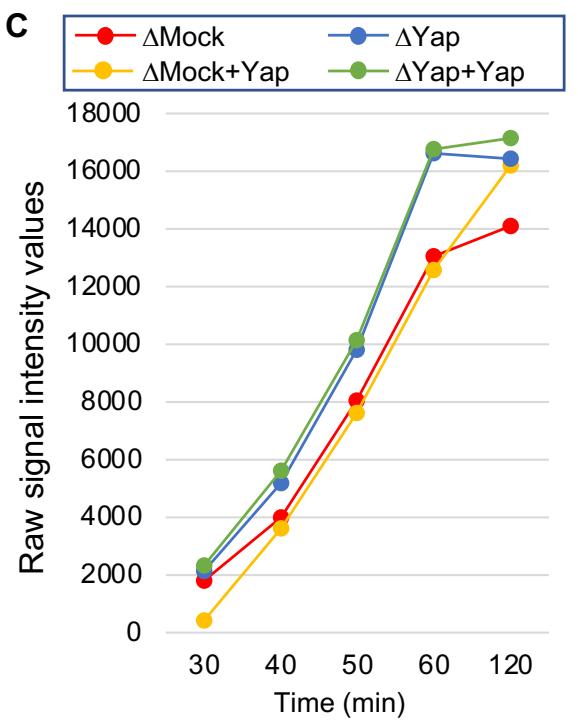

B
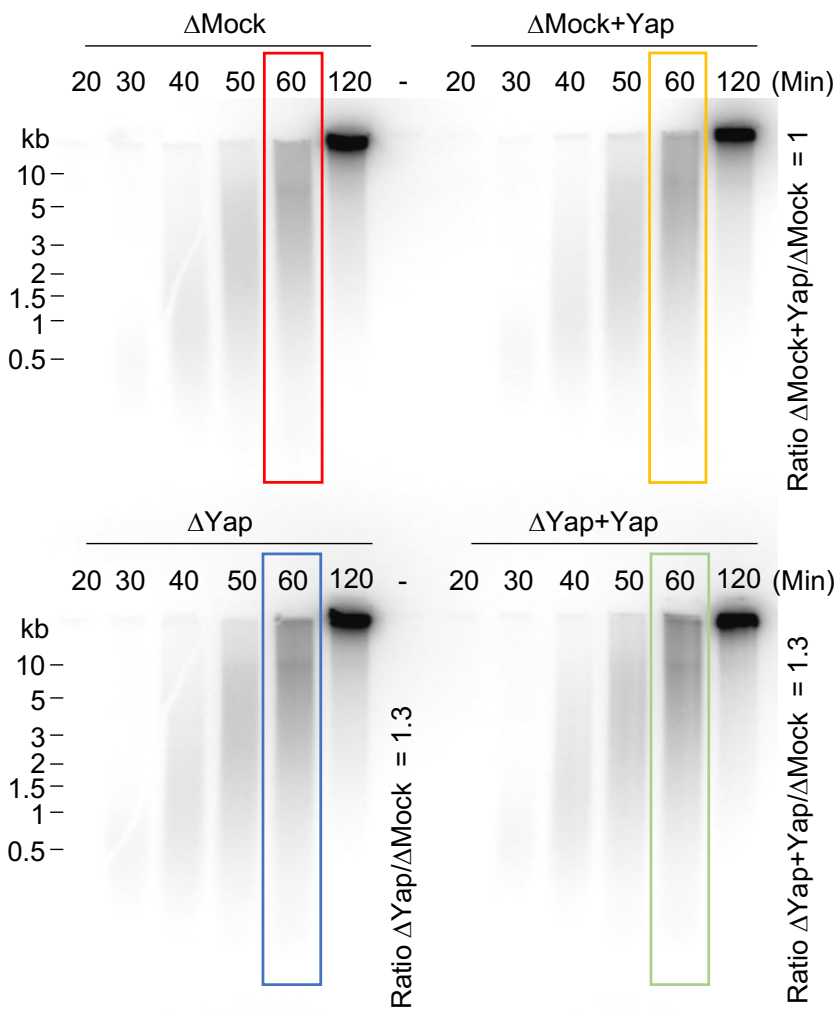

Figure 1 - figure supplement 3. Adding back recombinant Yap protein does not restore the rate of DNA synthesis in Yap-depleted extracts. (A) Western blot showing the levels of Yap in either wild type egg extracts (Extracts), depleted egg extracts ( $\Delta$ Mock and $\Delta$ Yap) or supplemented with Xenopus Yap recombinant protein produced in insect cells $(\Delta$ Mock + Yap and $\Delta$ Yap+Yap). (B, C) Nascent DNA strands synthesized were analyzed by alkaline gel electrophoresis after the indicated times (B). The level of radioactivity incorporation was quantified for each lane and plotted as raw intensity values (C). Ratios of the signal obtained in each condition over that of the $\Delta$ Mock at 60 minutes is indicated in (B) as examples like in Figure 1D. -, unloaded lane.

\section{Yap depletion increases replication origin firing}

The higher rate of DNA synthesis observed in the absence of Yap could result from either an increase in origin firing, an increase in fork speed, or both. To directly monitor origin activation on single DNA molecules, we performed DNA combing experiments in control and Yap depleted extracts and determined the replication content, fork density, distances between replication eyes and eye lengths (Figure 2A, B, Figure 2 - table supplement 1). After Yap depletion, the mean replicated fraction significantly increased during early and mid S-phase by 
2.5-fold (Figure 2B, C), consistent with the nascent strand analysis shown in Figure 1C. Moreover, Yap depletion significantly increased the mean density of active replication forks (1.8-fold; Figure 2D), demonstrating that the absence of Yap leads to an increase of activated replication origins. In parallel, a significant decrease in eye-to-eye distances occurred (ETED; Figure 2E). The increase of the overall fork density was more pronounced than the decrease of distances between neighbor origins analyzed at all time points (Figure 2, Figure 2 - table supplement 1). Therefore, this observation pointed to a role of Yap in regulating the activation of origins in not yet active, later replicating groups of origins. Replication eye lengths (EL) were not significantly different after Yap depletion at very early S-phase (Figure 2F), suggesting that fork speed was unchanged. Larger eye sizes detected at later time points (Figure 2 - table supplement 1) are most probably due to fusions of eyes from neighbor origins due to increased origin activation after Yap depletion, since we were not able to detect larger nascent strands in Yap depleted extracts during very early S-phase (Figure 1 - figure supplement 2). Altogether, we conclude that Yap depletion leads to an increase in origin activation, suggesting

A
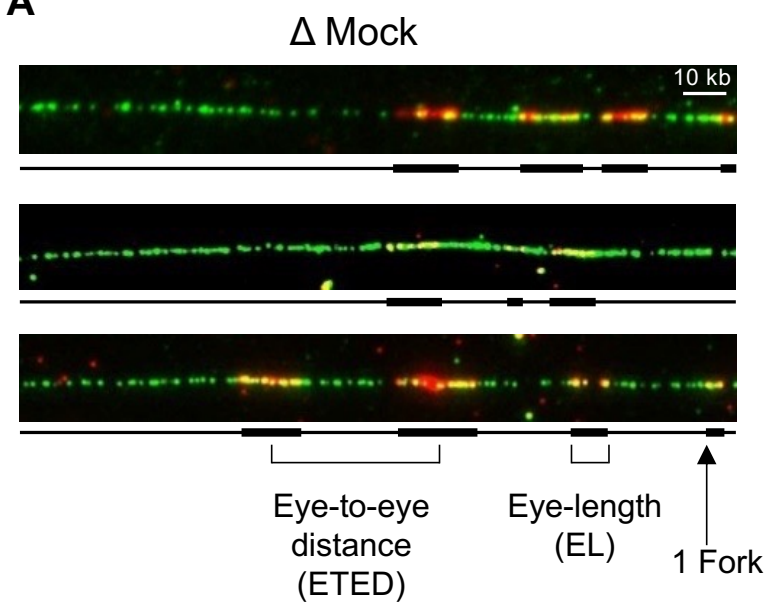

B

\begin{tabular}{|r|r|r|r|r|r|}
\hline & \multirow{2}{*}{ time } & \multicolumn{2}{|c|}{$\begin{array}{r}\text { replicated } \\
\text { fraction } \%\end{array}$} & \multicolumn{2}{c|}{$\begin{array}{r}\text { fork density } \\
(1 / 100 \mathrm{~kb})\end{array}$} \\
\hline & $\min$ & $\Delta$ Mock & $\Delta$ Yap & $\Delta$ Mock & $\Delta$ Yap \\
\hline \multirow{2}{*}{ replicate 1 } & 35 & 0.02 & 0.035 & 1.42 & 2.91 \\
\cline { 2 - 6 } & 55 & 0.148 & 0.445 & 3.14 & 5.51 \\
\hline \multirow{2}{*}{ replicate 2 } & 65 & 0.056 & 0.169 & 2.51 & 4.61 \\
\cline { 2 - 6 } & 80 & 0.105 & 0.226 & 3.34 & 5.25 \\
\hline
\end{tabular}

E
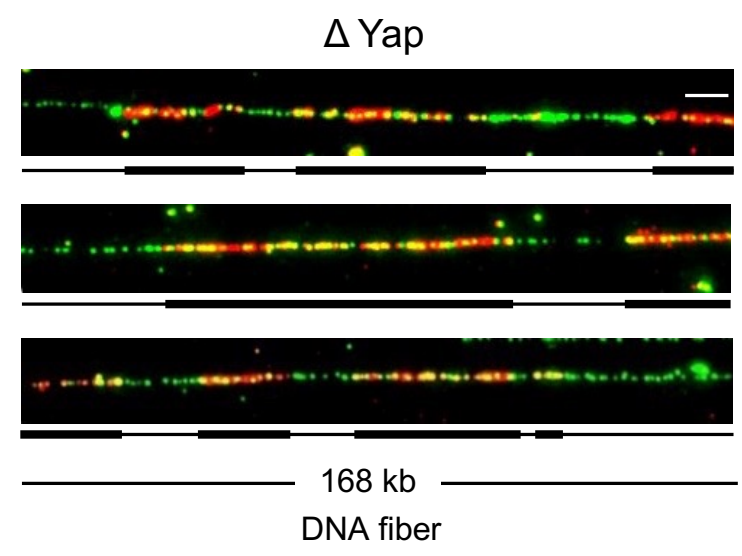

C

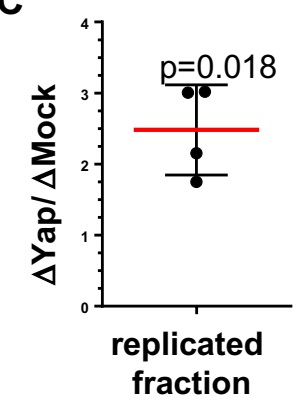

F

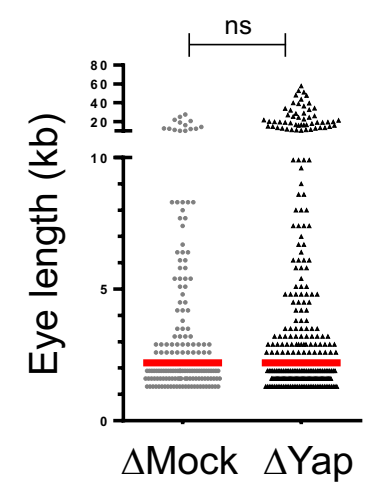

D

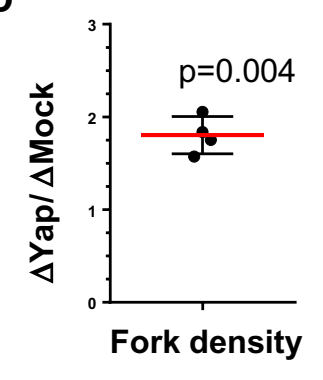


Figure 2. Egg extracts lacking Yap exhibit more active replication origins. Sperm nuclei were incubated in egg extracts in the presence of Biotin-dUTP and DNA combing was performed. (A) Three representative combed DNA fibers replicated in either the $\Delta$ Mock- or $\Delta$ Yap-depleted extracts (green: whole DNA labelling; red: biotin labelled replication eyes). (B) Replicated fraction and fork density $(1 / 100 \mathrm{~kb})$ of two independent experiments at 2 time points were calculated and reported in the table. (C, D) Corresponding scatter blots of $\Delta Y a p / \Delta$ Mock ratios of replicated fraction $(C)$ and fork density $(D)$, with mean $(n=4)$ and standard deviation, $\mathrm{P}$ values, one sample t-test, compared to theoretical mean 1. (E, F) The eye-to-eye distance distributions after mock or Yap depletion (E, ETED, scatter dot plots with median, $\mathrm{n}=157$ or 286 , replicate $2,80 \mathrm{~min}$ ) and the eye length distributions (F, EL, scatter dot plots with median, $11 \mathrm{n}=182$ or 311 , replicate $2,65 \mathrm{~min}$ ).

\begin{tabular}{|c|c|c|c|c|c|c|c|c|}
\hline \multirow{3}{*}{\begin{tabular}{|l} 
Time \\
Condition \\
\end{tabular}} & \multicolumn{4}{|c|}{ Replicate 1} & \multicolumn{4}{|c|}{ Replicate 2} \\
\hline & \multicolumn{2}{|c|}{$35 \mathrm{~min}$} & \multicolumn{2}{|c|}{$55 \min$} & \multicolumn{2}{|c|}{$65 \min$} & \multicolumn{2}{|c|}{$80 \min$} \\
\hline & $\Delta$ Mock & $\Delta$ Yap1 & $\Delta$ Mock & $\Delta$ Yap1 & $\Delta$ Mock & $\Delta$ Yap1 & $\Delta$ Mock & $\Delta$ Yap1 \\
\hline Analysed DNA (kb) & 4653.09 & 3773.9 & 11332.1 & 12784.59 & 15674.9 & 14752 & 18163.52 & 17709.8 \\
\hline Replicated DNA(kb) & 92.95 & 131.04 & 1674.66 & 5688.02 & 883.5 & 2498.88 & 1909.44 & 4003.2 \\
\hline Replicated fraction & 0.02 & 0.035 & 0.15 & 0.445 & 0.056 & 0.169 & 0.105 & 0.226 \\
\hline Number of analysed fibers & 91 & 94 & 197 & 214 & 145 & 197 & 221 & 192 \\
\hline Number of fully replicated fibers & 0 & 0 & 3 & 25 & 0 & 1 & 1 & 5 \\
\hline Number of unreplicated Fibers & 66 & 63 & 111 & 46 & 50 & 40 & 78 & 45 \\
\hline Mean size of all fibers $(\mathrm{kb})$ & 51.13 & 40.15 & 57.52 & 59.74 & 108.1 & 74.88 & 82.19 & 92.2 \\
\hline Number of replication eyes & 31 & 52 & 143 & 256 & 182 & 311 & 286 & 409 \\
\hline Mean Eye Length (EL) (kb) & 2.26 & 2.26 & 6.62 & 11.43 & 3.8 & 6.48 & 5.37 & 6.7 \\
\hline Median Eye Length (kb) & 1.2 & 1.3 & 3.5 & 7.3 & 2.2 & 2.2 & 2.2 & 2.9 \\
\hline Number of Eye to Eye Distances (ETED) & 7 & 24 & 71 & 147 & 93 & 170 & 157 & 286 \\
\hline Mean ETED length (kb) & 13.23 & 13.41 & 14.61 & 17.87 & 30.3 & 20.30 & 23.55 & 15.8 \\
\hline Median ETED length $(\mathrm{kb})$ & 11.3 & 8.6 & 12.5 & 13.5 & 19.7 & 14.1 & 17.8 & 11 \\
\hline Number of replication forks & 66 & 110 & 356 & 704 & 393 & 680 & 606 & 930 \\
\hline Fork Density (forks/100 kb) & 1.42 & 2.91 & 3.14 & 5.51 & 2.51 & 4.61 & 3.34 & 5.25 \\
\hline
\end{tabular}

Figure 2 - table supplement 1. Depletion of Yap increases replication origin firing. Raw analysis of two independent DNA combing experiments presented in Figure 2. The analysis was performed as described in Materials and Methods.

\section{Yap interacts with Rif1}

To identify Yap partners in the context of DNA replication, we conducted an exploratory search for Yap-interacting proteins by co-immunoprecipitation coupled to mass spectroscopy (co-IPMS) in S-phase egg extracts (see data availability). Among the proteins enriched more than 3fold in Yap-co-IP versus control-co-IP conditions, we mostly identified factors functionally associated with mRNA metabolic process, ribonucleoprotein complex assembly and translation (Figure 3A). This is in accordance with the fact that Xenopus egg extracts possess little or no intrinsic transcriptional activity but can strongly support translation and post-translational modification (Matthews and Colman, 1991). Of note, our analysis did not point to GO term enrichments related to DNA replication per se. However, we identified an interesting candidate, Rif1, a major factor of the replication timing program (Cornacchia et al., 2012; Yamazaki et al., 2012). Interestingly, both Yap and Rif1 are associated with the stem cell population maintenance GO term.

We confirmed this Yap/Rif1 interaction in egg extracts by reciprocal co-immunoprecipitation assays (Figure 3B). We next showed that this interaction between Rif1 and Yap also exists following the expression of the tagged proteins in HEK293 cells (Figure 3C). Altogether, our data uncovered Rif1 as a Yap interacting factor, supporting the role of Yap in the regulation of DNA replication dynamics. 

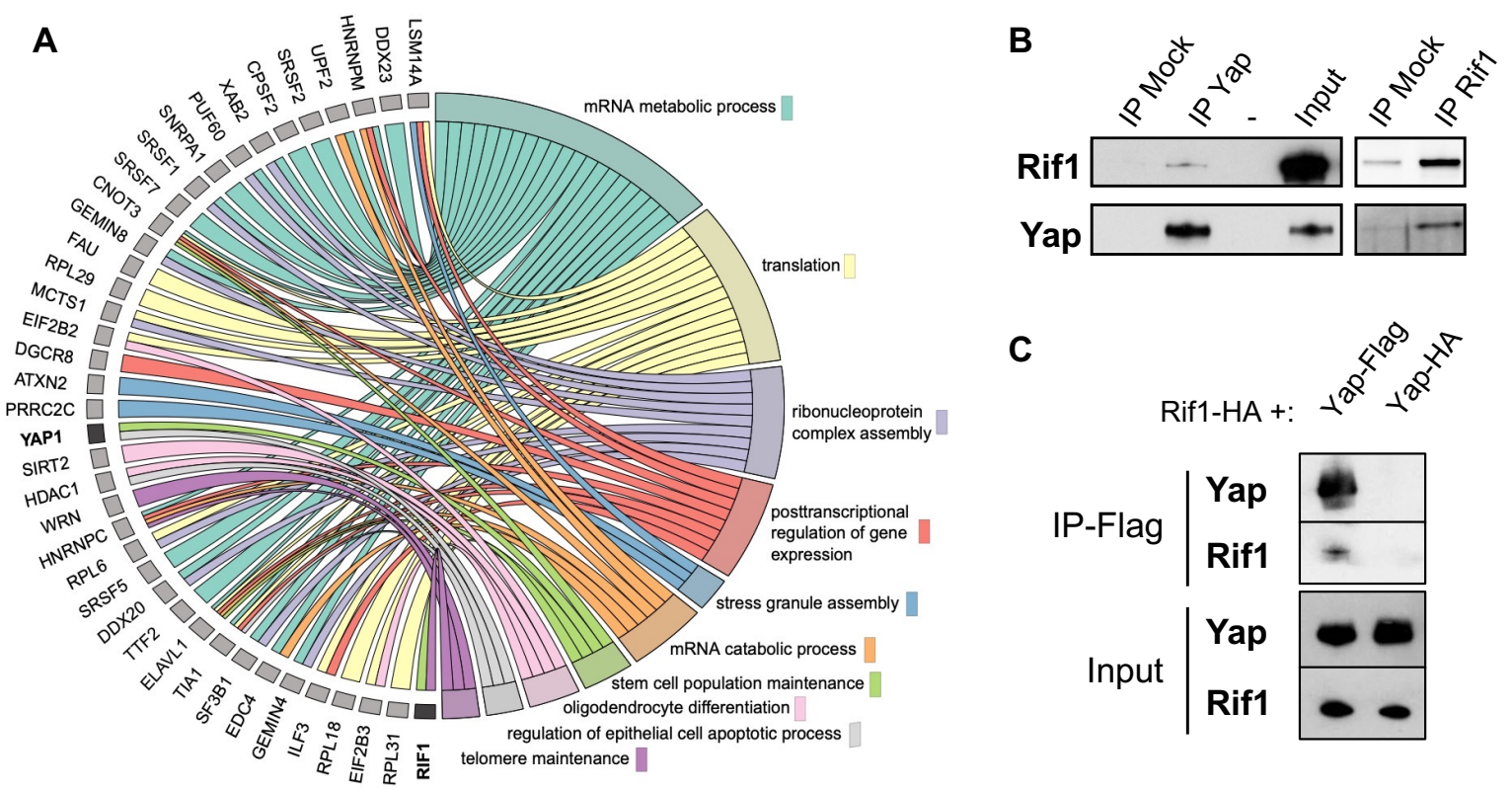

Figure 3. Rif1 interacts with Yap. (A) Chord plot representation related to GO annotations belonging to biological processes of proteins enriched by at least 3-fold in Yap versus control co-immunoprecipitations performed in S-phase egg extracts. Note that Yap and Rif1 are both functionally associated with stem cell population maintenance. (B) Anti-Yap (IP Yap), antiRif1 (IP Rif1) or control (IP Mock) antibodies coupled to Sepharose beads were incubated in S-phase egg extracts; immunoprecipitates were subjected to gel electrophoresis and western blotted using the indicated antibodies. -, unloaded lane. (C) Extracts from HEK293T cells transfected with the indicated tagged constructs were immunoprecipitated using anti-Flag antibody. The input and immunoprecipitates were subjected to gel electrophoresis and western blotted using the indicated antibodies.

\section{Yap and Rif1 depletions accelerate cell division rate in vivo in embryonic cells}

To assess whether Yap non-transcriptional function in DNA replication dynamics also holds true in vivo, we took advantage of the early cell divisions of Xenopus embryos that provide a simplified system of the cell cycle. Indeed, during early development prior to the mid-blastula transition (MBT, stage 8), cells divide very rapidly, rather synchronously for a series of 12 divisions and present a cell cycle structure without gap phases. As a result, variations of the number of cells at a given time during this developmental period reflect alteration of the time spent in the S and M phases. We thus decided to deplete embryos from Yap and assess the outcomes on the rate of embryonic cell division. Since Yap protein is maternally expressed (Figure 4A), we employed the recently developed Trim-Away technique (Clift et al., 2018, 2017; Weir et al., 2021) to directly trigger in vivo the degradation of Yap protein stockpile (Figure 4A). The Trim-Away mediated knockdown has previously been shown to be effective in Xenopus for another target using Trim 21 mRNAs (Weir et al., 2021). Here, we decided to use the Trim 21 protein instead, to prevent delay inherent to the translation process. In addition, since we observed an increase in the level of Yap protein before MBT (Figure 4A), we combined the Trim-Away approach with injections of yap translation blocking morpholino oligonucleotides (MO) to prevent de novo protein synthesis (Figure 4B). We found that Yap degradation was effective from the 8-cell stage onwards using the Trim-Away approach and that the combined strategy (Trim-Away + MO) led to a stronger and prolonged Yap depletion (Figure 4 - figure supplement 1A). We then monitored the progression of cell division before MBT. We found that cells were smaller and more numerous in Yap depleted embryos than in 
controls at stage 7 (Figure 4C, D). This suggests that Yap depletion leads to an increased speed of cell divisions in pre-MBT Xenopus embryos. The resulting embryos do develop but they display severe abnormalities by the tadpole stage (Figure 4 - figure supplement 1B).

4 We wondered whether the depletion of Rif1 could lead to a similar phenotype. Rifl depletion was previously shown to increase the rate of DNA replication in Xenopus egg extracts during unchallenged S-phase (Alver et al., 2017), but it was unknown how Rif1 depletion would affect early embryonic cell cycles in vivo. We undertook the same strategy to deplete Rifl from Xenopus embryos using both the Trim-Away technique and rifl-MO. We found that Rif1 depletion from embryos also led to an increased number of cells at stage 7, indicative of a faster rate of cell division, as previously observed upon Yap depletion (Figure 4 C, D). Considering the known function of Rifl in DNA replication and the absence of gap phases in pre-MBT embryos, our results strongly suggest that the increased rate of cell division in absence of Rif1 results from an acceleration of DNA replication and a shortening of S-phase length. We therefore propose that both Yap and Rif1 are involved in controlling the DNA replication dynamics in pre-MBT embryos.

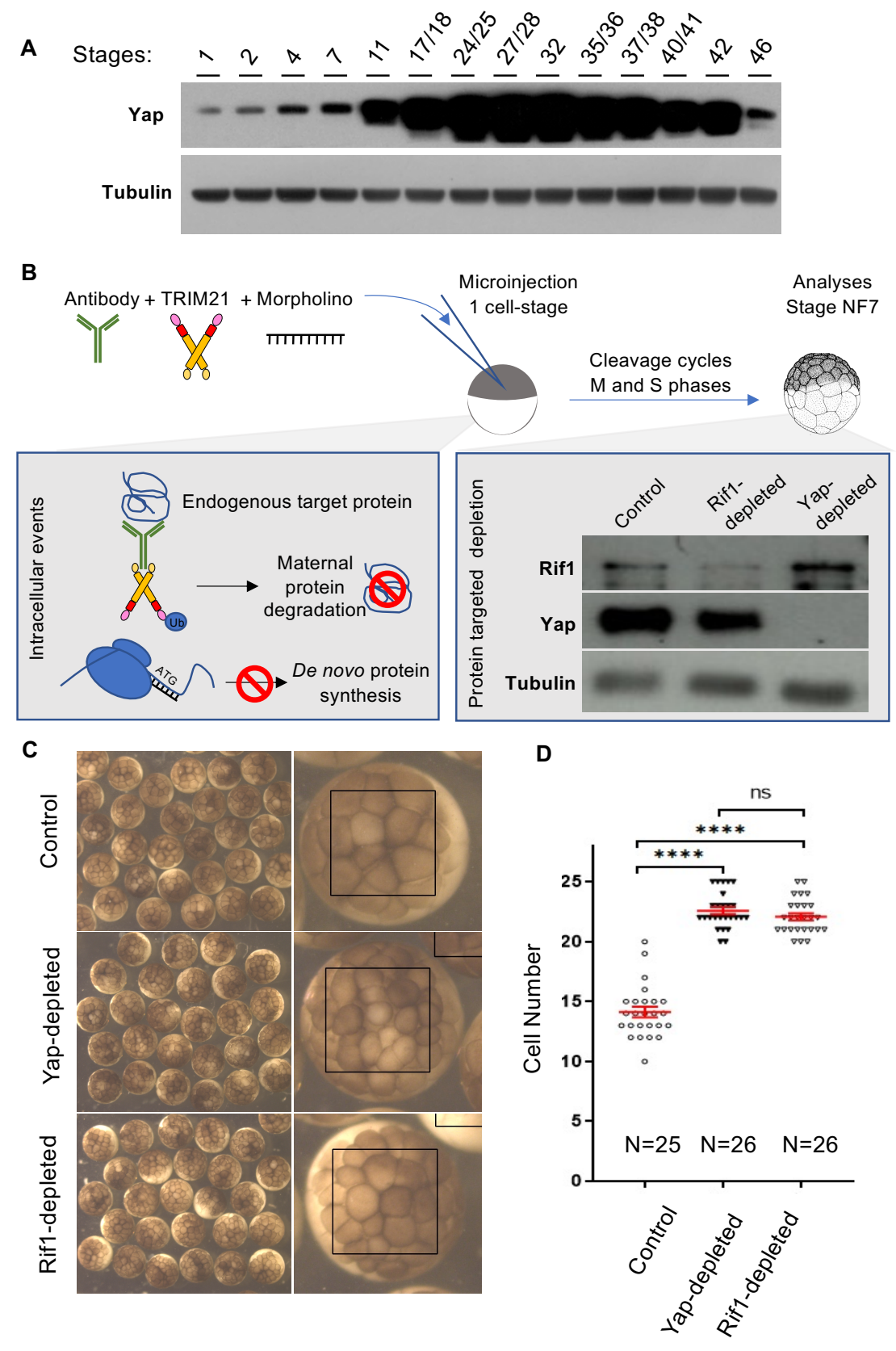


bioRxiv preprint doi: https://doi.org/10.1101/2021.11.18.468628; this version posted November $19,2021$. The copyright holder for this preprint (which was not certified by peer review) is the author/funder, who has granted bioRxiv a license to display the preprint in perpetuity. It is made available under aCC-BY-NC-ND 4.0 International license.

Figure 4. Yap and Rif1 depletion accelerate cell cycles in early Xenopus embryos. (A) Time course analysis of Yap expression throughout development by western blot. (B) Diagram of the experimental procedure used in (C) and western blot showing the efficiency of in vivo Yap and Rif1 depletions at stage 7 using combined Trim-Away and MO-mediated knock-down approaches. X. laevis embryos were microinjected at the one-cell stage with (i) control MO + pre-immune serum + TRIM21 (Control), (ii) Yap-MO + anti-Yap antibody + TRIM21 (Yapdepleted), or (iii) rifl-MO + anti-Rif1 antibody + TRIM21 (Rif1-depleted). (C) Images from representative injected stage 7 embryos. A close-up view is shown on the right panels for each condition. (D) The number of cells per embryo within the area defined in B (black boxes) was quantified. Data are shown as individual value plots with error bars (mean with SEM in red). Mann-Whitney test; $* * * * \mathrm{p} \leq 0.0001$; ns, not significant Scale bar $=500 \mu \mathrm{m}$.

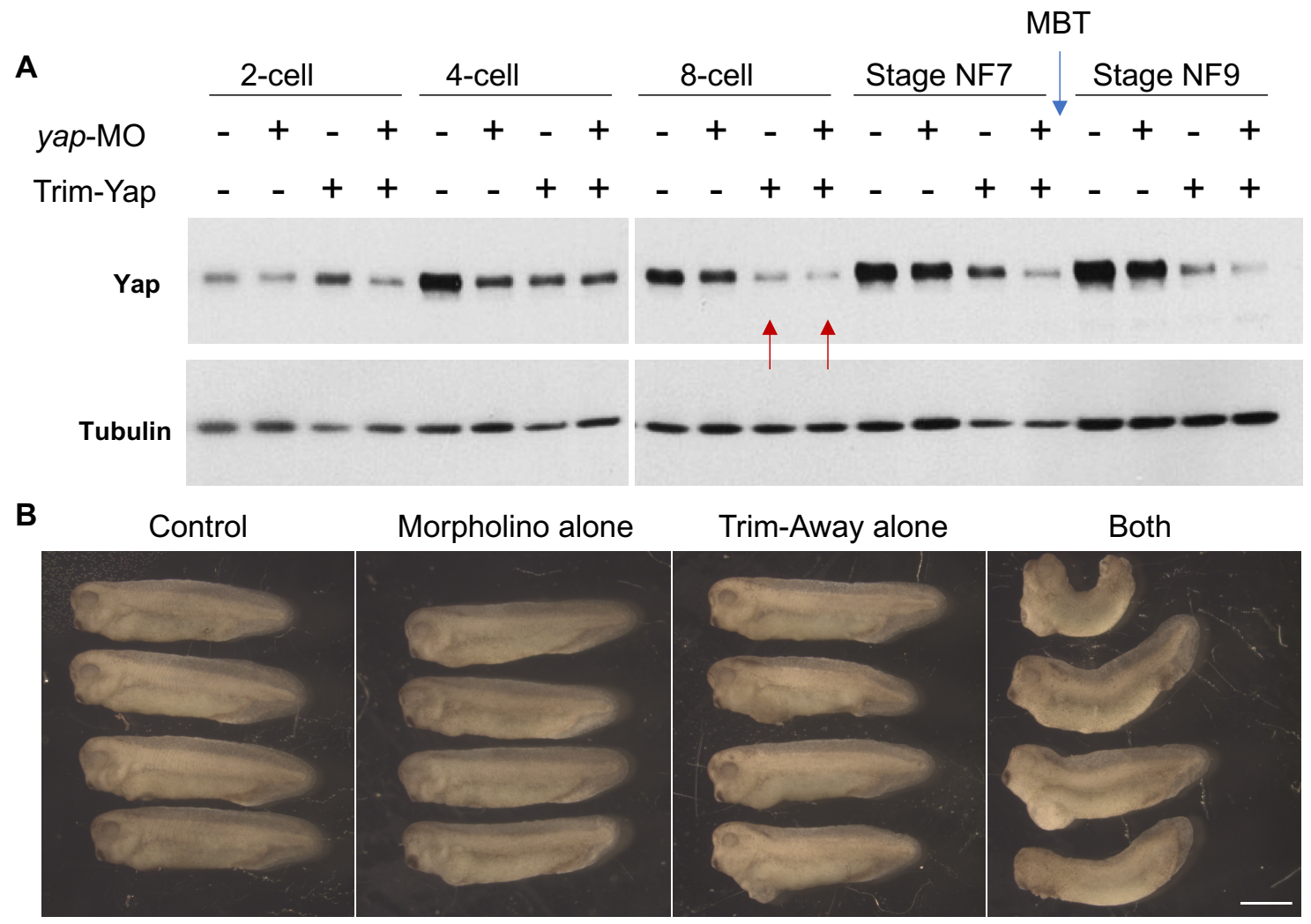

Figure 4 - figure supplement 1. Yap knockdown using the Trim-Away strategy is effective at very early stages of development and leads to severe developmental defects in tadpoles. (A) Western blot performed on whole protein extracts from a pool of 8 embryos injected with either control morpholinos (-) or yap morpholinos (yap-MO, + ), and/or pre-immune serum + TRIM21 (-) or anti-Yap antibodies + TRIM21 (Trim-Yap, +). Embryos were injected as described in Figure 4A then harvested at different times during development as indicated. The mid-blastula transition (MBT, blue arrow) is indicated as well as the time at which Yap depletion becomes observable (red arrows). (B) Injected embryos with (i) control MO + preimmune serum + TRIM21 (Control), (ii) yap-MO + pre-immune serum + TRIM21 (Morpholino alone), (iii) control MO + anti-Yap + TRIM21 (Trim-Away alone) or (iv) yap-MO + anti-Yap + TRIM21 (both), were allowed to develop until the tadpole stage (NF32-33). Pictures of 4 specimens are shown for each condition. Scale bar $=1 \mathrm{~mm}$. 
rif1 is expressed in retinal stem cells and its knockdown affects their temporal program of DNA replication

Since we found this new interaction between Rif1 and Yap and since Rif1 has been recently shown to function in a tissue-specific manner (Armstrong et al., 2020), we investigated its expression and function in Xenopus retina and compared the results with our previous findings regarding Yap retinal expression/function (Cabochette et al., 2015). In situ hybridization study and immunostaining experiments revealed prominent rifl expression in the periphery of the ciliary marginal zone (CMZ) of the retina (Figure 5A-C), a region containing stem and early progenitor cells (Perron et al., 1998), and where yap is also specifically expressed (Cabochette et al., 2015). We next undertook a knockdown approach using rifl-MO (Figure 5D-F). Morphant tadpoles exhibited significantly reduced eye size compared to controls (Figure 5E, F), as did Yap morphants (Cabochette et al., 2015). Importantly, in support of the specificity of rifl-MO, this phenotype was restored upon co-injection of a rifl-MO with non-targetable rifl mRNAs (Figure 5 - figure supplement 1).

A

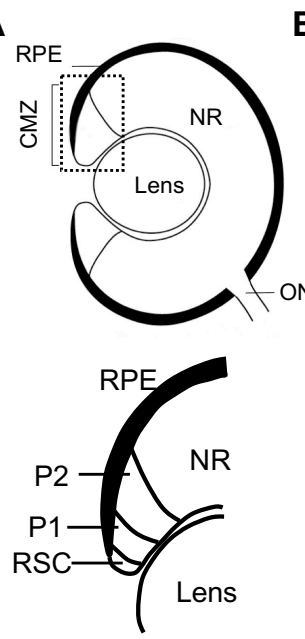

B
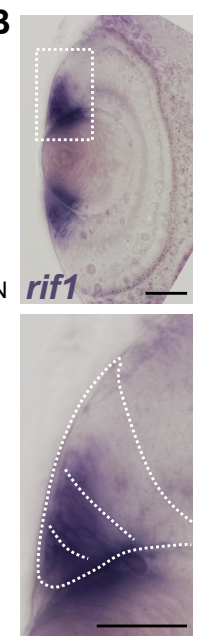
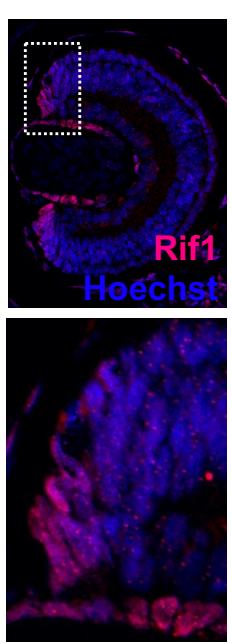

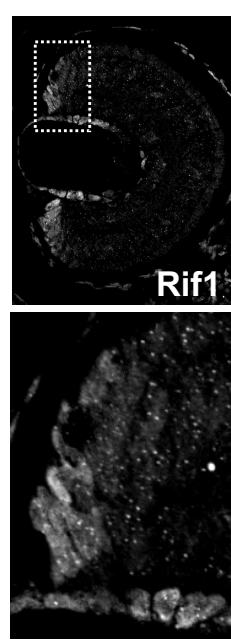

Rif1

C

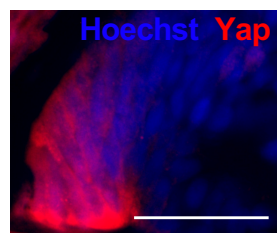

E
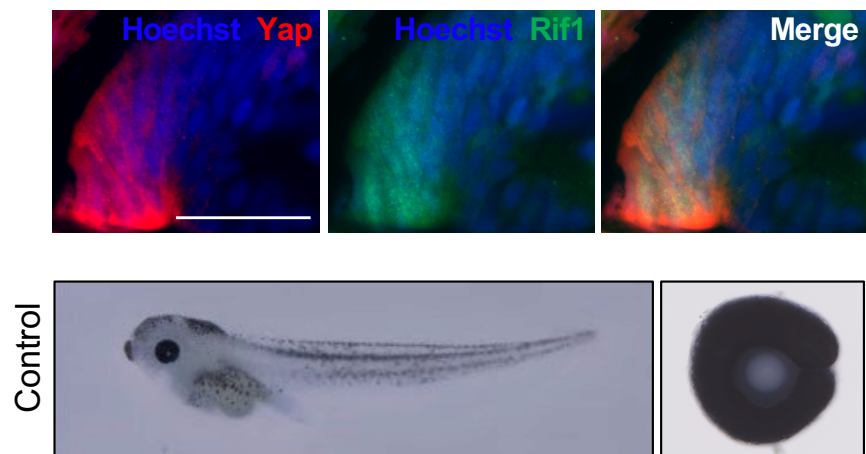

$\sum_{\substack{1 \\ !}}^{0}$

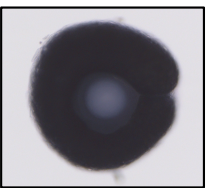

Figure 5. rif1 is expressed in retinal stem cells and its knock-down leads to small eye phenotype. (A) Schematic transversal section of a Xenopus tadpole retina (RPE: retinal pigmented epithelium; NR: neural retina; ON: optic nerve). Within the ciliary marginal zone (CMZ; lower diagram), retinal stem cells (RSC) reside in the most peripheral margin while early (P1) and late (P2) progenitors are located more centrally. (B) Retinal sections from stage 41 Xenopus tadpoles following in situ hybridization for rifl expression (left panels, in purple) or immunostained for Rif1 (middle panel in red along with nuclei counterstained with Hoechst 
in blue, and right panel Rif1 alone in white). The images on the lower panels are higher magnification of the $\mathrm{CMZ}$ (delineated dotted lines on the top panels). (C) CMZ region of retinal sections from stage 41 Xenopus tadpoles co-immunostained for Yap (red) and Rif1 (green) along with nuclei counterstained with Hoechst (blue). (D) Diagram showing the experimental procedure used in (E). One cell-stage embryos are microinjected with Control MO or rifl-MO and analyzed at stage 41 . The western blot shows the efficiency of the MO at depleting Rifl in embryos. (E) Tadpoles microinjected with MO as shown in (D) and corresponding dissected eyes (right panels). (F) The area of dissected eyes was measured for 10 embryos per condition. Data are shown as individual value plots with error bars (mean with SEM in red). MannWhitney test; $* * * \mathrm{p}=0.0002$. Scale bar $=50 \mu \mathrm{m}$ in (B, C), $1 \mathrm{~mm}$ in (E, tadpoles) and $100 \mu \mathrm{m}$ in (E, dissected eyes).

A

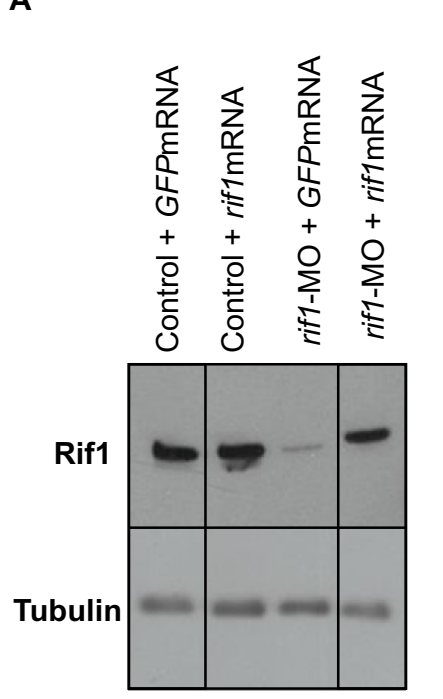

\section{B}

Control-MO + GFPmRNA

Control-MO + rif1mRNA

rif1-MO + GFPmRNA

rif1-MO + rif1mRNA

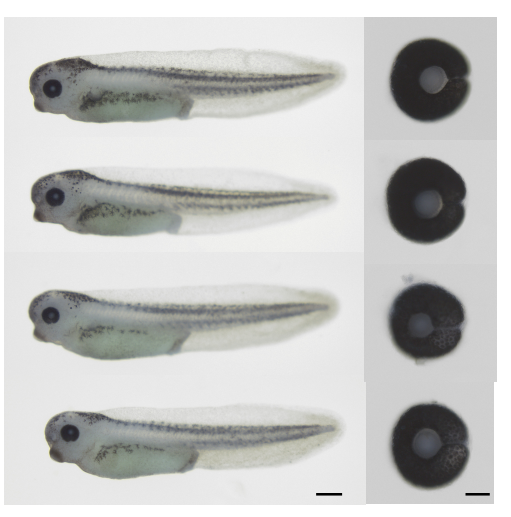

ns

C

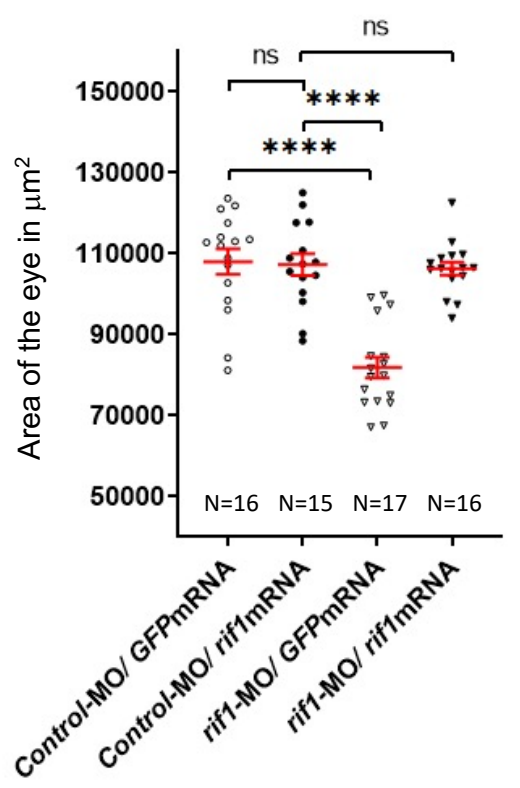

Figure 5 - figure supplement 1 . The rif1-MO-induced small eye phenotype is rescued by co-injection with rif1 mRNA (A) Western blot analysis showing the levels of Rif1 proteins in tadpoles at stage 41 following microinjection at 1 cell-stage of either Control-MO (Control) or rifl-MO together with GFP mRNA used as a control or rifl mRNA. Tubulin is used as a loading control. (B) Lateral views and dissected eyes of stage 41 tadpoles following one-cell stage microinjection of MO and mRNA as indicated. (C) Quantification of dissected eye areas. The rifl-MO-induced small eye phenotype is rescued by co-injection of rifl mRNA. Of note a suboptimal dose of rifl mRNA was used for the rescue experiment so that it does not alone generate any eye phenotype. The number of analyzed tadpoles is indicated for each condition. Data are shown as individual value plots with error bars (mean with SEM in red). Scale bar = $500 \mu \mathrm{m}$ for tadpoles and $50 \mu \mathrm{m}$ for dissected eyes. 
1 We next analyzed the level of proliferation within the CMZ in rif1 morphant tadpoles (Figure 2 6). Unlike the observed decreased of the EdU cell number in yap morphant CMZ (Cabochette 3 et al., 2015), we did not find here any significant difference in the number of EdU+ cells in rifl4 MO-injected tadpoles compared to controls (Figure 6E). Interestingly however, as observed in yap morphants (Cabochette et al., 2015), we found a drastic change in the distribution of EdUlabelled replication foci in retinal stem and early progenitor cells, where rifl is normally expressed (Figure 6 A-D, F). Short pulse labelling experiments indeed allow the visualization of replication foci in cells. The spatial distribution of these foci evolves in a stereotyped manner during S-phase (Figure 6A): from numerous small foci located throughout the nucleus in early S-phase, to few large punctuated ones in mid/late S-phase (Koberna et al., 2005; Van Dierendonck et al., 1989). Our analysis revealed a decreased proportion of cells exhibiting a mid-late versus early S-phase patterns in rif1 morphants compared to controls (Figure 6F). We thus propose that, like yap knockdown, rifl knockdown alters the spatial organization of replication foci in CMZ cells, suggesting that both Yap and Rif1 may control the RT program in vivo in post-embryonic retinal stem/early progenitor cells.

A

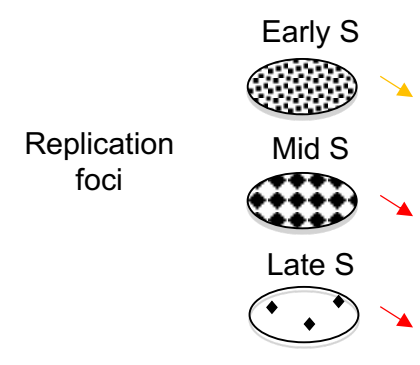

C
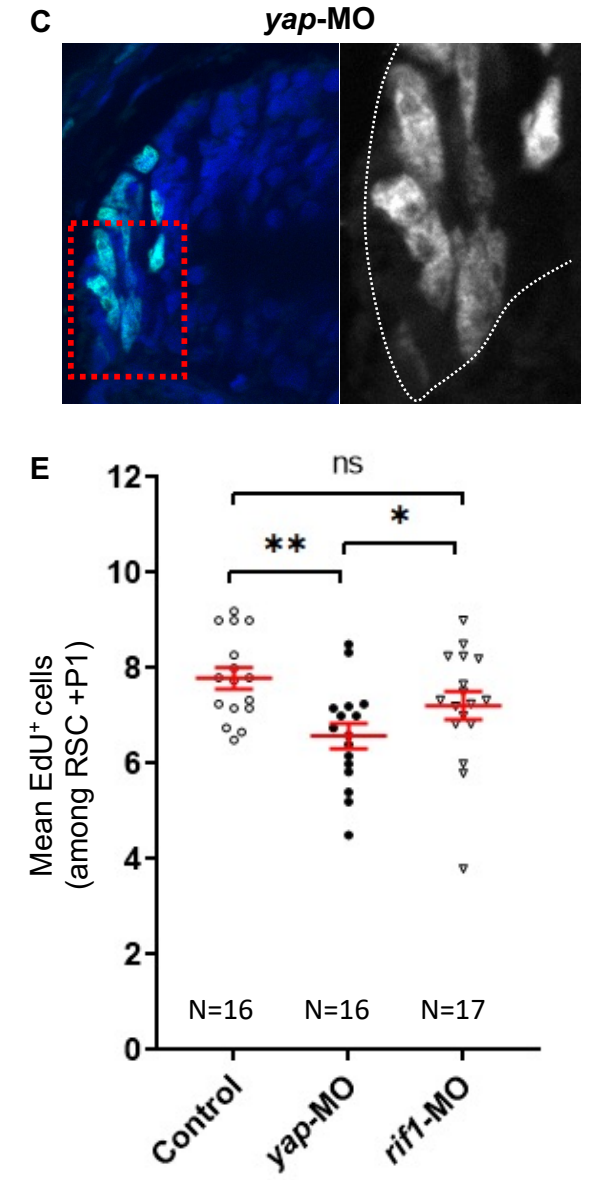

B
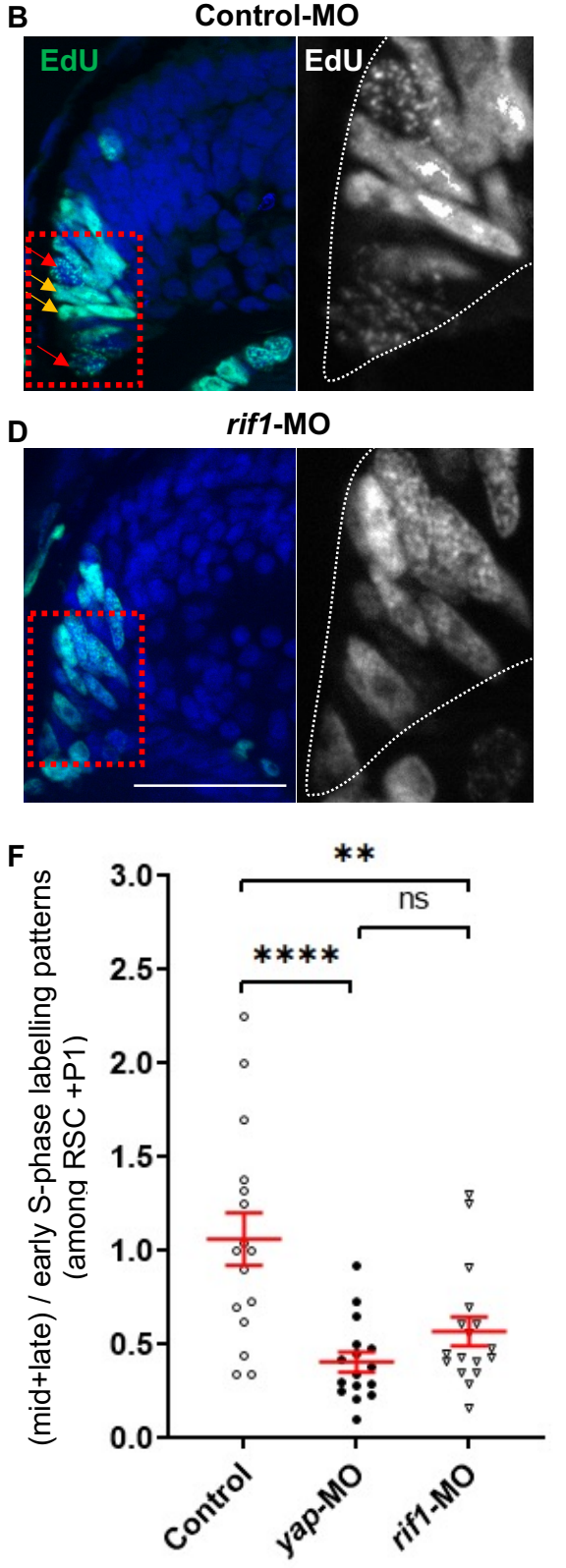
1 Figure 6. rif1 loss of function affects DNA replication timing in retinal stem/early

2 progenitor cells. (A) Schematic representation of the replication foci observed during S-phase 3 progression as inferred from EdU labelling. Orange arrows indicate typical early S replication 4 patterns and red arrows, mid/late $\mathrm{S}$ replication ones (only 2 examples of each are shown in panel B). (B-D) One cell-stage embryos are microinjected with either the control MO (B), yap$\mathrm{MO}(\mathbf{C})$ or rifl-MO (D) and analyzed for EdU-labelled replication foci (1 hr.-pulse) at stage 41. The region enlarged on right panels is delineated with red dashed lined boxes. The tip of

8 the CMZ is highlighted by dotted white lines in the enlargements. (E, F) Quantifications of $9 \mathrm{EdU}^{+}$cell number $(\mathrm{E})$ and of the ratio of mid+late/early-like foci patterns $(\mathrm{F})$. In both cases, 10 only cells in the RSC and P1 regions (see diagram shown in Figure 5A) have been analyzed. 11 The number of analyzed retinas is indicated for each condition. Data are shown as individual 12 value plots with error bars (mean with SEM in red). Mann-Whitney test; ** $\mathrm{p} \leq 0.01,{ }^{*} \mathrm{p}=0.05$; 13 in $* * * * \mathrm{p} \leq 0.0001$; ns, non-significant. Scale bar $=50 \mu \mathrm{m}$. 


\section{Discussion}

2

During S-phase, eukaryotic DNA is not replicated all at once, but large genomic regions are duplicated in a characteristic temporal order known as the RT program. To date, very few factors involved in the orchestration of this program have been identified. We have previously revealed that yap knockdown is associated with an altered RT program in Xenopus retinal stem cells (Cabochette et al., 2015). Whether and how Yap could directly regulate DNA replication was however unknown. Here, we used the Xenopus in vitro replication system and early Xenopus embryos, where DNA transcription is absent, to study the role of Yap in S-phase, independently from its transcriptional function. Our study shows that Yap regulates DNA replication dynamics in these embryonic systems. First, we found that Yap is recruited to chromatin at the start of DNA synthesis, and this is dependent on the pre-replicative complex assembly. Second, our data revealed a non-transcriptional role for Yap in the initiation of DNA replication. Third, we identified Rif1, a global regulator of the RT program, as a novel Yap partner. Finally, our in vivo data suggest that Yap and Rifl are similarly involved in both the spatial organization of DNA replication foci and DNA replication dynamics. We propose a model in which Yap and Rifl would limit replication origin firing and as such act as breaks during S-phase to control the overall rate of DNA synthesis (Figure 7).

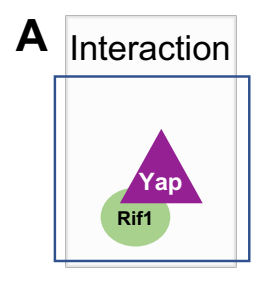

B
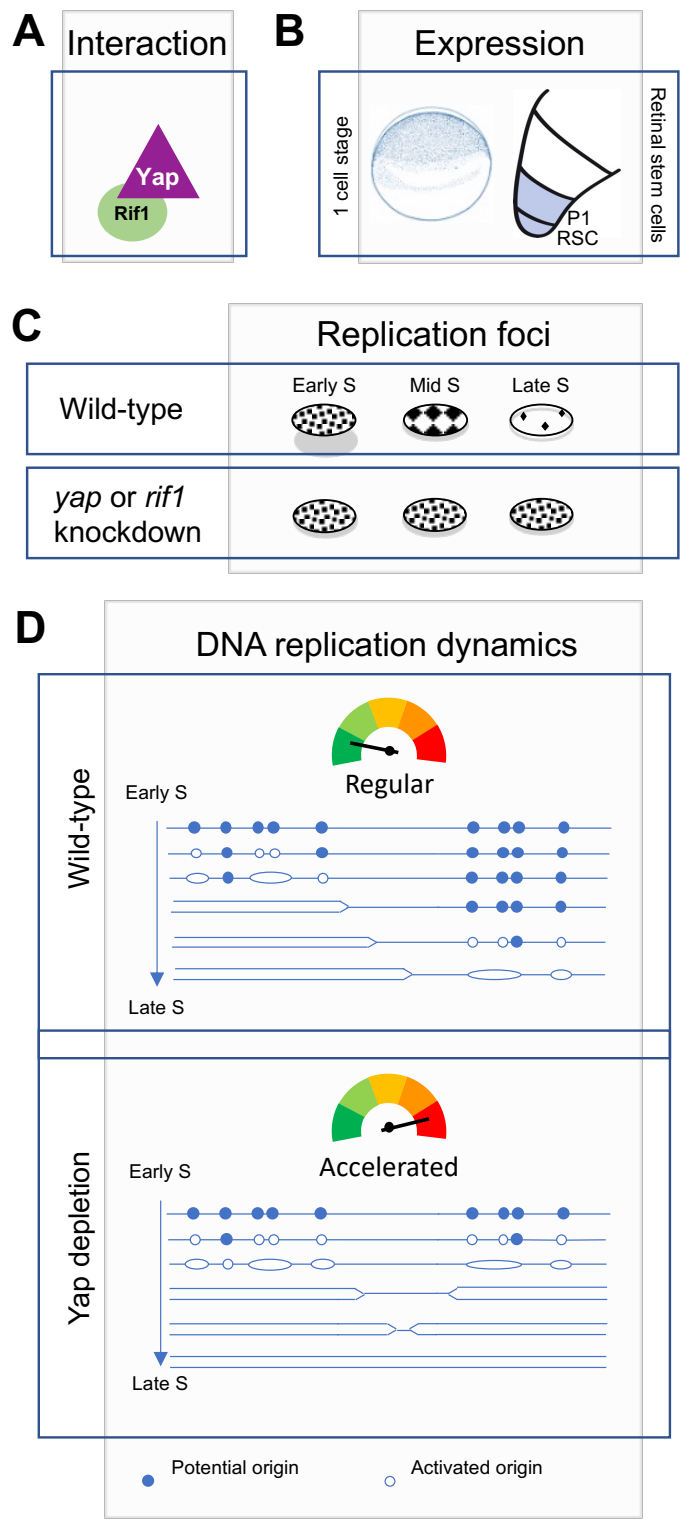
Figure 7. Diagram illustrating Yap function in the control of DNA replication dynamics. We found that Yap and Rifl can interact (A) and are co-expressed in Xenopus early embryos as well as in retinal stem/progenitor cells (B). (C) We found that yap and rifl knockdowns in retinal stem/progenitor cells similarly alter the proper repartition of early and late-like patterns of replication foci (this study and (Cabochette et al., 2015)). (D) We propose a model where Yap would ensure the proper orchestration of the RT program during early development. The schematic representation of the replication program was adapted from Gaboriaud J. and Wu PJ (Gaboriaud and $\mathrm{Wu}, 2019$ ). Based on our assays in vitro in egg extracts and in vivo in early embryos, we propose that following Yap depletion (bottom panel), the number of firing origins is increased and S-phase length is reduced compared to a wild-type situation (top panel).

The molecular control of the RT program remains elusive. Regarding key factors, Rif1 was the first mammalian factor shown to temporally control DNA replication, acting negatively on origin activation (Cornacchia et al., 2012; Hayano et al., 2012; Yamazaki et al., 2013, 2012). This function of Rif1 depends on its interaction with protein phosphatase 1 (PP1) (Davé et al., 2014) which counteracts the DDK dependent activation of MCM2-7. On the other hand, Pololike kinase 1 (Plk1) positively controls replication origin firing by negatively regulating Rif1PP1 interaction (Ciardo et al., 2021b). Here, we found that Yap is a novel key component of this molecular machinery that regulates replication origin activation. First, we found that Yap and Rif1 interact physically. Whether this interaction could impact Rif1-PP1 association remains to be determined. Interestingly, it has previously been shown that PP1 interacts with and dephosphorylates Yap (Wang et al., 2011), suggesting the potential existence of a YapRif1-PP1 multi-protein complex. Second, we found that Yap depletion leads to similar DNA replication dynamics defects than those obtained following Rifl depletion in early embryos. Third, in egg extracts Yap depletion increases the overall rate of DNA replication, similarly to what was shown before in the absence of Rif1 in the same in vitro system (Alver et al., 2017). Finally, we also observed similar phenotypes following rifl or Yap knockdown in Xenopus early embryos (i.e. increase in cell cycle speed) and in retinal stem cells (i.e. increase in earlylike replication foci patterns). It is thus tempting to speculate that Rif1 and Yap act in concert to regulate replication dynamics.

We observed that Yap is recruited to replication competent chromatin at the start of S-phase and accumulates over S-phase, consistent with a direct role in DNA replication regulation. This dynamic behavior is similar to the observed increase of chromatin bound Rif1 (Kumar et al., 2012). We showed that Yap loading on chromatin depends on a functional pre-RC assembly or on DNA replication per se, since inhibition of pre-RC assembly also inhibits S-phase entry. We however do not know how Yap is recruited to chromatin in the first place since our proteomic analysis did not reveal a direct interaction with any members of the pre-RC complex. Therefore, Yap might be recruited by proteins involved in steps downstream of pre-RC assembly. We found that the increased rate in DNA synthesis after Yap depletion is due to an increase in replication origin activation, especially early in S-phase, strongly suggesting that Yap directly limits origin-firing. Whether it prevents late origin firing in early S-phase cells or whether it inhibits dormant origin firing around active replication forks remains to be investigated. However, the increase in early-like foci patterns at the expense of late-like ones in retinal stem cells observed upon yap (Cabochette et al., 2015) or rifl knockdown (this study) rather suggests an impact on the partition between early and late replication-firing. In Rifl-depleted Hela cells, the overall replication foci were similarly found to be extensively rearranged, with cells displaying predominantly early S-phase-like patterns (Yamazaki et al., 2012). In addition, our DNA combing analysis after Yap depletion demonstrated that the overall fork density was increased to a higher extent than local origin distances were decreased. This suggests that Yap 
controls origin firing more at the level of groups of origins or replication clusters than at the level of single origins, therefore regulating more the temporal control of origin activation.

In embryos, the increased speed of cell division during early embryonic cleavage cycles that we observed upon yap or rifl knockdown is consistent with a function of both factors in limiting the replication of late genomic regions leading to a slowing down of S-phase. In retinal stem cells however, Yap and Rifl do not seem to function similarly on S-phase length. Indeed, although knockdown phenotypes were similar in terms of early-late foci ratio regulation, only Yap knockdown led to a significant change in the proportion of S-phase cells among stem and progenitor cells (i.e. number of EdU+ cells at the tip of the CMZ). How S-phase length is differentially regulated in both cases following altered RT program remains to be investigated. It is well known that Yap also transcriptionally regulates cell cycle genes, which may contribute to such different outcomes. Interestingly, among direct targets genes regulated by Yap, there are also essential factors involved in replication licensing, DNA synthesis and repair (e.g. CDC6, GINS1, MCM3, MCM7, POLA2, POLE3, TOP2A and RAD18; (Zanconato et al., 2015)). Yap thus likely impacts replication dynamics at both the transcriptional and non-transcriptional levels in retinal stem cells.

Combined observations point to a role for Rif1 in higher order chromatin architecture and its relationship with RT (Foti et al., 2016). Rifl localizes to late-replicating sites of chromatin and acts as a remodeler of the three-dimensional (3D) genome organization and as such defines and restricts the interactions between replication-timing domains (Foti et al., 2016). Although the RT program can be established independently of the spatial distribution of replication foci, nuclear organization and RT are correlated and Rif1 is central in co-regulating both processes (Gnan et al., 2021). It would thus be interesting in the future to assess whether Yap function in DNA replication could be linked to a role as an organizer of nuclear architecture. Recent studies invoke liquid-liquid phase separation (LLPS) in the establishment of chromatin activity and the formation of chromatin compartments (Rippe, 2021). Interestingly, Yap has been described to form liquid like condensates in the nucleus (Cai et al., 2019). Whether higher level replication organization is impacted by LLPS is currently unknown, but several members of the pre-RC complex (Orc1, Cdc6, Cdt1) are also able to induce DNA dependent liquid-liquid phase separations in vitro (Parker et al., 2019).

Not much is known about signaling pathways regulating the RT or Rifl activity. The ATM/53BP1 signaling pathway has been identified upstream of the RT and relays information onto Rif1 activity in response to DNA double strand breaks (Kumar and Cheok, 2014). Future work will be required to assess whether Yap activity in the context of DNA replication is regulated by the Hippo pathway. Interestingly, LATS1, another component of the Hippo pathway, has been involved in the ATR-mediated response to replication stress (Pefani et al., 2014). Several Hippo pathway components may thus regulate, independently or in concert, replication dynamics.

The role of Yap and Rif1 in the regulation of the RT program in early embryos opens new questions regarding the dynamics of RT changes during development. Although it was previously thought that the spatio-temporal replication program is not established until the MBT (Hyrien et al., 1995; Sasaki et al., 1999), it was also demonstrated that the oocyte-type of 5S RNA genes replicate later than the somatic-types of 5S RNA genes in Xenopus egg extracts (Wolffe, 1993). It was then shown that the RT program in Xenopus in vitro system is not completely random, with large chromosomal domains being replicated in a reproducible manner (Labit et al., 2008). Moreover, in zebrafish embryos, a genome-wide approach clearly 
1 established that a compressed, yet defined, RT program is evident before the MBT (Siefert et 2 al., 2017). Further on, it was recently demonstrated that the replication program is regulated at 3 the level of large domains by the replication checkpoint (Ciardo et al., 2021a) and by polo-like 4 kinase 1 via the inhibition of Rif1/PP1 (Ciardo et al., 2021b). Altogether, those findings 5 strongly suggest the existence of an embryonic RT program before the MBT. Remarkably, 6 gradual changes in the RT program occur from the MBT and throughout development. The 7 molecular control behind this dynamic is unknown. How Yap and Rifl functions evolve at 8 different stages and impact changes in the RT program at this important transition is therefore 9 an interesting issue to be addressed in the future. To do so, the new combination of tools 10 implemented in this study will be very valuable, as we have proven the efficient depletion of 11 maternal proteins stockpiles while preventing their de novo synthesis by combining the TrimAway technique with MO injections before MBT. In this context, Xenopus embryos seem particularly suitable to shed light and dissect the molecular mechanisms at work during embryogenesis that underlie RT changes. Identifying and characterizing the factors controlling these changes during development will certainly have an impact on how we approach questions related to cellular reprogramming, stem cells and cancer biology. 


\section{Materials and Methods}

\section{Ethics statement}

All animal experiments have been carried out in accordance with the European Community Council Directive of 22 September 2010 (2010/63/EEC). All animal care and experimentation were conducted in accordance with institutional guidelines, under the institutional license C 91471-102. The study protocols were approved by the institutional animal care committee CEEA \#59 and received an authorization by the Direction Départementale de la Protection des Populations under the reference APAFIS\#998-2015062510022908v2 for Xenopus experiments.

\section{Embryo, tadpole and eye collection}

Xenopus laevis embryos were obtained by conventional methods of hormone-induced egg laying and in vitro fertilization (Sive et al., 2007), staged according to Nieuwkoop and Faber's table of development (Nieuwkoop and Faber, 1994), and raised at $18-20^{\circ} \mathrm{C}$. Before whole eye dissection, tadpoles were anesthetized in $0.005 \%$ benzocaine. Dissected eye area was measured using AxioVision REL 7.8 software (Zeiss).

\section{Antibodies and recombinant proteins}

A detailed list of the antibodies used in this study for immunohistochemistry (IHC), immunodepletion and western blot (WB) is provided in Supplementary table. HLTV-hTRIM21 was a gift from Leo James (Addgene plasmid \#104973; http://n2t.net/addgene:104973; RRID: Addgene_104973). Recombinant His-geminin, and His-hTRIM21 were prepared as described (respectively (Clift et al., 2017; Toyoshima and Hunter, 1994). C-terminal Xenopus rifl cloned in pET30a vector (a gift from W. Dunphy and A. Kumagai (Kumar et al., 2012)), was expressed in Escherichia coli C41 cells, purified by Nickel-Sepharose chromatography (Amersham Bioscience), and used as an antigen to raise antibodies in rabbits at a commercial facility (Covalab, Villeurbanne, France). A cDNA encoding recombinant His-tagged Xenopus Yap was cloned in pFastBaclvector, expressed in the baculovirus Bac-to-Bac expression system (Invitrogen), purified by Nickel-Sepharose chromatography as described by the supplier (Amersham Bioscience) and then dialyzed overnight against $25 \mathrm{mM}$ Hepes pH 7.8, $250 \mathrm{mM}$ $\mathrm{NaCl}, 5 \mathrm{mM}$ imidazole, 5\% glycerol, $7.5 \mathrm{mM} \mathrm{MgCl} 2,1 \mathrm{mM}$ DTT, 1 mM EDTA. Purified HisYap was then used as an antigen to raise antibodies in rabbits at a commercial facility (Covalab, Villeurbanne, France).

\section{Morpholinos and TRIM21 microinjections}

For in vivo depletion experiments, 2 pmol of Yap-Morpholinos (MO, Gene Tools, LLC) or 1 pmol of rifl-MO or 2 pmol of standard control MO together with a fluorescent tracer (dextran fluorescein lysine, Thermo Fisher Scientific) were microinjected into fertilized eggs. The TrimAway experiments were conducted in a similar way using a mixture of recombinant hTRIM21, anti-Rifl or anti-Yap antibody together with 1 or 2 pmol of rifl-, Yap- or control-MO. MO sequences used in this study can be found in Supplementary table.

\begin{tabular}{|c|c|c|c|c|}
\hline \multicolumn{5}{|l|}{ List of antibodies. } \\
\hline Antigen & Host & Supplier / Cat. Number & $\begin{array}{c}\text { Antibody } \\
\text { Registry (RRID) } \\
\text { or DOI } \\
\end{array}$ & Application \\
\hline & \multicolumn{4}{|c|}{ Primary antibodies } \\
\hline Anti-human MCM2 & Mouse & $\begin{array}{l}\text { Bethyl lab, Euromedex, } \\
\text { Souffelweyersheim, France / A300-191A }\end{array}$ & AB_162709 & $1: 2000(\mathrm{WB})$ \\
\hline
\end{tabular}


bioRxiv preprint doi: https://doi.org/10.1101/2021.11.18.468628; this version posted November 19, 2021. The copyright holder for this preprint (which was not certified by peer review) is the author/funder, who has granted bioRxiv a license to display the preprint in perpetuity. It is made available under aCC-BY-NC-ND 4.0 International license.

\begin{tabular}{|c|c|c|c|c|}
\hline Anti-Xenopus MCM7 & Rabbit & Gift from R. A. Laskey & $\begin{array}{l}10.1073 / \text { pnas.93. } \\
19.10189\end{array}$ & $1: 1000(\mathrm{WB})$ \\
\hline Anti- $\alpha$ Tubulin & Mouse & $\begin{array}{l}\text { Sigma, Saint-Quentin-Fallavier, France / } \\
\text { T5168 }\end{array}$ & AB_477579 & $1: 10000(\mathrm{WB})$ \\
\hline Anti-rat PCNA & Mouse & $\begin{array}{l}\text { ThermoFisher, Illkirch, France / MA5- } \\
11358\end{array}$ & AB_10982348 & $1: 50(\mathrm{WB})$ \\
\hline Anti-human Yap & Mouse & Abcam Cambridge, UK / Ab56701 & AB_2219140 & $\begin{array}{l}1: 1000(\mathrm{WB}) \\
1: 50(\mathrm{IHC})\end{array}$ \\
\hline Anti-human Yap & Rabbit & Abcam Cambridge, UK / Ab62752 & AB 956477 & Immunodepletion, IP \\
\hline Anti-human $\mathrm{H} 3$ & Mouse & Abcam Cambridge, UK / Ab1791 & $\mathrm{AB} 302613$ & $1: 1000(\mathrm{WB})$ \\
\hline Anti-Flag & Rabbit & $\begin{array}{l}\text { Cell Signaling, OZYME, Saint-Cyr- } \\
\text { l'École, France / F7425 }\end{array}$ & AB_439687 & IP \\
\hline Anti-human ssDNA & Mouse & $\begin{array}{l}\text { Merck Millipore, Guyancourt, France / } \\
\text { MAB3034 }\end{array}$ & AB_11212688 & 1:50 (DNA combing) \\
\hline & \multicolumn{4}{|c|}{ Primary antibodies made for this study } \\
\hline Anti-Xenopus Yap & Rabbit & Covalab, Bron, France & & $\begin{array}{l}\text { 1:100 (IHC), 1:2000 } \\
\text { (WB), Trim away }\end{array}$ \\
\hline Anti-Xenopus Rif1 & Rabbit & Covalab Bron, France & $\begin{array}{l}10.1093 / \mathrm{nar} / \mathrm{gkab} \\
756\end{array}$ & $\begin{array}{l}1: 100 \text { (IHC), } 1: 2000 \\
\text { (WB), Trim away }\end{array}$ \\
\hline & \multicolumn{4}{|c|}{ Secondary antibodies } \\
\hline Anti-Mouse IgG & Rabbit & $\begin{array}{l}\text { Sigma, Saint-Quentin-Fallavier, France / } \\
\text { M7023 }\end{array}$ & AB_260634 & Immunodepletion \\
\hline Anti-mouse Alexa 488 & Rabbit & ThermoFisher, Illkirch, France / A11059 & AB_2534106 & $\begin{array}{l}\text { 1:50 (DNA combing) } \\
1: 50 \text { (IHC) }\end{array}$ \\
\hline Anti-rabbit Alexa 448 & Goat & ThermoFisher, Illkirch, France / A11008 & AB_143165 & 1:50 (DNA combing) \\
\hline Anti-mouse Alexa 594 & Goat & ThermoFisher, Illkirch, France / A11005 & AB_2534073 & $\begin{array}{l}\text { 1:50 (DNA combing) } \\
1: 1000 \text { (IHC) }\end{array}$ \\
\hline Anti-mouse Alexa 488 & Rabbit & ThermoFisher, Illkirch, France / A11001 & AB 2534069 & $1: 1000(\mathrm{IHC})$ \\
\hline $\begin{array}{l}\text { Anti-streptavidin } \\
\text { biotinylated }\end{array}$ & Mouse & Eurobio, Les Ulis, France / BA-0500 & AB_2336221 & $\begin{array}{l}\text { 1:50 (DNA combing) } \\
1: 50 \text { (IHC) }\end{array}$ \\
\hline Streptavidin Alexa 594 & & ThermoFisher, Illkirch, France / S11227 & AB_2313574 & 1:50 (DNA combing) \\
\hline Anti-mouse IgG HRP & Goat & $\begin{array}{l}\text { Sigma, Saint-Quentin-Fallavier, France / } \\
\text { A4416 }\end{array}$ & AB_258167 & $1: 10000(\mathrm{WB})$ \\
\hline Anti-rabbit IgG HRP & Donkey & GE Healthcare, France / NA934 & AB_772206 & $1: 10000(\mathrm{WB})$ \\
\hline \multicolumn{5}{|c|}{ IHC, immunohistochemistry; WB, western blot; IP immunoprecipitation; RRIDs, Research Resource Identifiers } \\
\hline \multicolumn{5}{|l|}{ List of Morpholinos. } \\
\hline \multicolumn{2}{|l|}{ yap-MO } & \multicolumn{3}{|c|}{ 5' TAGGAGACTGTGPGTCACTTCACC 3', } \\
\hline \multicolumn{2}{|l|}{ rifl-MO } & \multicolumn{3}{|c|}{ 5' AATCCACAGAACAGACGACAGCCAT 3' } \\
\hline \multicolumn{2}{|c|}{ Control (GeneTools Standard Control) } & \multicolumn{3}{|c|}{ 5' CСТCTTACCTCAGTTACAATTTATA 3' } \\
\hline
\end{tabular}

\section{Supplementary table}

\section{Replication of sperm nuclei in Xenopus egg extracts}

Replication competent extracts from unfertilized Xenopus eggs and sperm nuclei from testis of male frogs were prepared as described (Blow and Laskey, 1986). Sperm nuclei (2000 nuclei/ $\mu 1)$ were incubated in untreated, mock or Yap depleted extracts in the presence of cycloheximide to inhibit translation $(250 \mu \mathrm{g} / \mathrm{ml}$, Sigma), energy mix ( $7.5 \mathrm{mM}$ creatine phosphate, $1 \mathrm{mM} \mathrm{ATP}$, $0.1 \mathrm{mM}$ EGTA, pH 7.7, $1 \mathrm{mM} \mathrm{MgCl}_{2}$ ). Loading of the MCM complex (pre-RC assembly) was prevented by addition of $100 \mathrm{nM}$ of recombinant geminin to the extracts.

\section{Immunodepletions}

Rabbit anti-Yap antibody (ab62752, Abcam), pre-immune serum or rabbit IgG (M7023, Sigma) were coupled overnight at $4{ }^{\circ} \mathrm{C}$ to protein A Sepharose beads (GE Healthcare). Coupled beads were washed three times in EB buffer ( $50 \mathrm{mM}$ Hepes, $\mathrm{pH} 7.5,50 \mathrm{mM} \mathrm{KCl}, 5 \mathrm{mM} \mathrm{MgCl}_{2}$ ) then incubated 1 hour at $4^{\circ} \mathrm{C}$ in egg extracts (volume ratio $1: 3$ ). 


\section{Neutral and alkaline agarose gel electrophoresis}

2 Sperm nuclei were incubated in fresh extracts complemented with indicated reagents and one(Invitrogen protocol) followed by ethanol precipitation, separated on $1.1 \%$ alkaline agarose gels, and analyzed as described (Marheineke and Hyrien, 2001). From one extract to another, the replication extent (percent of replication) differs at a specific time point, because each egg extract replicates nuclei with its own replication kinetics. In order to compare different independent experiments performed using different egg extracts, the data points of each sample were normalized to maximum incorporation value of $0-100 \%$. To include statistics, the scaled data points were grouped into 4 bins $(0-25 \%=$ early; $26-50 \%=$ mid; $51-75 \%=$ late; $76-100 \%$ $=$ very late $\mathrm{S}$ phase); mean and standard deviation were calculated for each bin and a Wilcoxon signed ranked test was used to assess statistically significant differences between the data in each bin.

\section{Western blot}

For analysis of chromatin-bound proteins, we used a protocol slightly modified from (Räschle et al., 2008). Briefly, reactions were diluted into a 13-fold volume of ELB buffer (10 mM Hepes $\mathrm{pH} 7.5,50 \mathrm{mM} \mathrm{KCl}, 2.5 \mathrm{mM} \mathrm{MgCl}_{2}$ ) containing $1 \mathrm{mM}$ DTT, $0.2 \%$ Triton X100, protease inhibitors and phosphatase inhibitors. Chromatin was recovered through a $500 \mathrm{mM}$ sucrose cushion in ELB buffer at $6780 \mathrm{~g}$ for $50 \mathrm{sec}$ at $4^{\circ} \mathrm{C}$, washed twice with $200 \mu 1$ of $250 \mathrm{mM}$ sucrose in ELB buffer, and resuspended in $20 \mu 1$ SDS sample buffer. Western blots were conducted using standard procedures on Xenopus embryo/tadpole protein extracts. Proteins were loaded, separated by $7.5 \%, 12 \%$ or $4-15 \%$ SDS-polyacrylamide gels (Bio-Rad) and transferred into nitrocellulose or Immobilon ${ }^{\circledR} \mathrm{P}$ membranes. Membranes were subsequently incubated with the indicated primary antibodies followed by the appropriate horseradish peroxidase-labelled antibodies (1/10000, Sigma-Aldrich or GE Healthcare, see Supplementary table). Immunodetection was performed using Super Signal West Pico or Femto Chemiluminescence Kit (Pierce). Quantification was done using Fiji software (Schindelin et al., 2012)).

\section{Molecular combing and detection by fluorescent antibodies}

DNA was extracted and combed as described (Marheineke et al., 2009). Biotin was detected with AlexaFluor594 conjugated streptavidin followed by anti-avidin biotinylated antibodies. This was repeated twice, then followed by mouse anti-human ssDNA antibody, AlexaFluor488 rabbit anti-mouse, and AlexaFluor488 goat anti-rabbit for enhancement (Gaggioli et al., 2013). Images of the combed DNA molecules were acquired and measured as described (Marheineke et al., 2009). The fields of view were chosen at random. Several hundred of DNA fibers were analyzed for each experiment. Measurements on each molecule were made using Fiji software (Schindelin et al., 2012) and compiled using macros in Microsoft Excel. Replication eyes were defined as the incorporation tracks of biotin-dUTP. Replication eyes were considered to be the products of two replication forks, incorporation tracks at the extremities of DNA fibers were considered to be the products of one replication fork. Tracts of biotin-labelled DNA needed to be at least $1 \mathrm{~kb}$ to be considered significant and scored as eyes. When the label was discontinuous, the tract of unlabeled DNA needed to be at least $1 \mathrm{~kb}$ to be considered a real gap. The replication extent was determined as the sum of eye lengths divided by the total DNA length. Fork density was calculated as the total DNA divided by the total number of forks. The midpoints of replication eyes were defined as the origins of replication. Eye-to-eye distances (ETED), also known as inter-origin distances, were measured between the midpoints of adjacent replication eyes. Incorporation tracks at the extremities of DNA fibers were not regarded as replication eyes but were included in the determination of the replication extent or replicated fraction, calculated as the sum of all eye lengths (EL) divided by total DNA. Scatter 
plots of ETED and EL were obtained using GraphPad version 6.0 (La Jolla, CA, USA). Statistical analyses of repeated experiments have been included as means or medians including standard deviations or ranks as indicated in the legends. A p value $\leq 0.05$ was considered significant.

\section{Immunostaining and EdU labelling}

For immunostaining, tadpoles were anesthetized in $0.005 \%$ benzocaine (Sigma), fixed in $1 \mathrm{X}$ PBS, $4 \%$ paraformaldehyde $1 \mathrm{~h}$ at room temperature and dehydrated, then embedded in paraffin and sectioned $(12 \mu \mathrm{m})$ with a Microm HM 340E microtome (Thermo Scientific). Immunostaining on retinal sections was performed using standard procedures. For proliferative cell labelling, tadpoles were injected intra-abdominally, 1-hour prior fixation, with 50-100 nl of $1 \mathrm{mM}$ 5-ethynyl-2'-deoxyuridine (EdU, Invitrogen) at stage 41. EdU incorporation was detected on paraffin sections using the Click-iT EdU Imaging Kit according to manufacturer's recommendations (Invitrogen).

Fluorescent images were taken with the AxioImagerM2 with Apotome (Zeiss) coupled to digital AxiocamMRc camera (Zeiss) and processed with the Axio Vision REL 7.8 (Zeiss) and Adobe Photoshop CS4 (Adobe) software. For quantifications of labelled cells by manual cell counting in the CMZ, a minimum of 16 retinas were analyzed. All experiments were performed at least in duplicate.

\section{Co-Immunoprecipitation}

Immunoprecipitations from HEK293T cells expressing either HA- or FLAG-tagged Yap were performed using the Dynabeads Protein A Immunoprecipitation Kit (Invitrogen) by coupling 5 $\mu \mathrm{g}$ of anti-FLAG (Cell signaling) to the beads and following the manufacturer's protocol. Immunoprecipitations from Xenopus egg extracts were performed as described below for mass spectrometry using rabbit anti-Yap (ab62752, Abcam) or rabbit anti-RIF antibodies. The 7.5\% polyacrylamide gel was further analyzed by western blot using Mouse anti-Yap or rabbit antiRIF antibodies

Antibodies used for immunoprecipitation are listed in Supplementary table.

\section{Mass spectrometry}

Rabbit anti-Yap antibody (ab62752, Abcam) or rabbit IgG (M7023, Sigma) were coupled $2 \mathrm{~h}$ at RT to protein A Sepharose beads (GE Healthcare). Coupled beads were covalently crosslinked using dimethyl pimelimidate according to standard procedures, washed with PBS and kept in PBS, $0.02 \%$ sodium azide at $4{ }^{\circ} \mathrm{C}$. For IP experiments, crosslinked beads with rabbit anti-Yap antibody or rabbit IgG were washed three times in EB buffer (50 mM Hepes, pH 7.5, $50 \mathrm{mM} \mathrm{KCl}, 5 \mathrm{mM} \mathrm{MgCl} 2$ ) and were incubated in Xenopus egg extracts for $30 \mathrm{~min}$ at $4{ }^{\circ} \mathrm{C}$. Beads were isolated by centrifugation and washed three times with $\mathrm{EB}$ buffer and once in EB buffer, $0.01 \%$ Tween 20 . The immunoprecipitated proteins were eluted by 2 X Laemmli buffer and collected after centrifugation. Approximately $20 \mathrm{ng}$ of immunoprecipitated Yap protein fraction was loaded on a $7.5 \%$ polyacrylamide gel and analyzed by mass spectrometry. Approximately $20 \mathrm{ng}$ of immunoprecipitated Yap protein fraction was loaded on a $7.5 \%$ polyacrylamide gel and analyzed by mass spectrometry (Protéomique Paris Saclay-CICaPS platform). Protein samples were reconstituted in solvent A (water/ACN [98: $2 \mathrm{v} / \mathrm{v}]$ with 0.1\% formic acid) and separated using a C18-PepMap column (Thermo Fisher Scientific) with a solvent gradient of $2-100 \%$ Buffer B ( $0.1 \%$ formic acid and $98 \%$ acetonitrile) in Buffer A at a flow rate of $0.3 \mu 1 / \mathrm{min}$. The peptides were electrosprayed using a nanoelectrospray ionization source at an ion spray voltage of $2300 \mathrm{eV}$ and analyzed by a NanoLC-ESI-Triple TOF 5600 system (AB Sciex). Protein identification was based on a threshold protein score of $>1.0$. For 
1 quantitation, at least two unique peptides with $95 \%$ confidence and a p-value $<0.05$ were 2 required.

3 Comprehensive protein list analysis and enriched biological pathways were based on Gene 4 ontology classification system using Metascape (Sajgo et al., 2017). Data visualization was 5 done using GOPlot R package (Livak and Schmittgen, 2001).

6

7 Quantification and statistical analyses

8 For quantifications of labeled $\mathrm{EdU}^{+}$cells by manual cell counting in the CMZ, 16 to 11 retinas

9 per conditions with a minimum of 2 sections per retina were analyzed. Dissected eye areas and 10 the number of cells per embryo were measured using Adobe Photoshop CS4 software. All 11 experiments were performed at least in duplicate. Shown in figures are results from one 12 representative experiment unless specified.

13 Statistical analyses (GraphPad Prism software, version 8.3.0) were performed using a Mann14 Whitney test or Wilcoxon signed ranked test as mentioned in the figure legends.

15

\section{Data availability}

17 The mass spectrometry proteomics data sets have been deposited to the ProteomeXchange 18 Consortium via the PRIDE (Perez-Riverol et al., 2019) partner repository with the dataset 19 identifiers PXD029345 and 10.6019/PXD029345. 


\section{Acknowledgements}

3 We are thankful to A. Kumagai and B. Dunphy for the gift of the C-terminal Xenopus Rif1 4 containing plasmid and Xenopus Rifl antibody. We are grateful to A. Donval for her help with 5 frog fertilizations and Virginie Chiodelli for technical support. This research was supported by 6 grants to M.P. from ARC (Association pour la Recherche sur le Cancer), Association Retina 7 France, Fondation Valentin Haüy, and UNADEV (Union Nationale des Aveugles et Déficients 8 Visuels) in partnership with ITMO NNP (Institut Thématique Multi-Organisme Neurosciences, 9 sciences cognitives, neurologie, psychiatrie) / AVIESAN (alliance nationale pour les sciences 10 de la vie et de la santé). RMG was a Conacyt fellow (grant number 439641). This work has 11 benefited from the facilities and expertise of the I2BC proteomic platform (Proteomic-Gif, 12 SICaPS) supported by IBiSA, Ile de France Region, Plan Cancer, CNRS and Paris-Sud 13 University. 


\section{References}

Alver RC, Chadha GS, Gillespie PJ, Blow JJ. 2017. Reversal of DDK-Mediated MCM Phosphorylation by Rif1-PP1 Regulates Replication Initiation and Replisome Stability Independently of ATR/Chk1. Cell Rep 18:2508-2520. doi:10.1016/j.celrep.2017.02.042 Armstrong RL, Das S, Hill CA, Duronio RJ, Nordman JT. 2020. Rif1 Functions in a TissueSpecific Manner to Control Replication Timing through Its PP1-Binding Motif. Genetics 215:75-87. doi:10.1534/genetics.120.303155

Bell SP, Kaguni JM. 2013. Helicase loading at chromosomal origins of replication. Cold Spring Harb Perspect Biol 5. doi:10.1101/cshperspect.a010124

Berezney R, Dubey DD, Huberman JA. 2000. Heterogeneity of eukaryotic replicons, replicon clusters, and replication foci. Chromosoma 108:471-484. doi:10.1007/s004120050399

Blow JJ, Gillespie PJ, Francis D, Jackson DA. 2001. Replication origins in Xenopus egg extract are 5-15 kilobases apart and are activated in clusters that fire at different times. $J$ Cell Biol 152:15-25. doi:10.1083/jcb.152.1.15

Blow JJ, Laskey RA. 2016. Xenopus cell-free extracts and their contribution to the study of DNA replication and other complex biological processes. Int J Dev Biol 60:201-207. doi:10.1387/ijdb.160142jb

Blow JJ, Laskey RA. 1986. Initiation of DNA replication in nuclei and purified DNA by a cell-free extract of Xenopus eggs. Cell 47:577-587. doi:10.1016/0092-8674(86)90622-7

Cabochette P, Vega-Lopez G, Bitard J, Parain K, Chemouny R, Masson C, Borday C, Hedderich M, Henningfeld KA, Locker M, Bronchain O, Perron M. 2015. YAP controls retinal stem cell DNA replication timing and genomic stability bis. Elife 4. doi: $10.7554 /$ eLife. 08488

Cai D, Feliciano D, Dong P, Flores E, Gruebele M, Porat-Shliom N, Sukenik S, Liu Z, Lippincott-Schwartz J. 2019. Phase separation of YAP reorganizes genome topology for long-term YAP target gene expression. Nat Cell Biol 21:1578-1589. doi:10.1038/s41556-019-0433-z

Ciardo D, Haccard O, Narassimprakash H, Arbona JM, Hyrien O, Audit B, Marheineke K, Goldar A. 2021a. Organization of dna replication origin firing in xenopus egg extracts: The role of intra-s checkpoint. Genes (Basel) 12. doi:10.3390/genes 12081224

Ciardo D, Haccard O, Narassimprakash H, Cornu D, Guerrera IC, Goldar A, Marheineke K. 2021b. Polo-like kinase 1 (Plk1) regulates DNA replication origin firing and interacts with Rif1 in Xenopus. Nucleic Acids Res 49:9851-9869. doi:10.1093/nar/gkab756

Clift D, McEwan WA, Labzin LI, Konieczny V, Mogessie B, James LC, Schuh M. 2017. A Method for the Acute and Rapid Degradation of Endogenous Proteins. Cell 171:16921706.e18. doi:10.1016/j.cell.2017.10.033

Clift D, So C, McEwan WA, James LC, Schuh M. 2018. Acute and rapid degradation of endogenous proteins by Trim-Away. Nat Protoc 13:2149-2175. doi:10.1038/s41596018-0028-3

Cornacchia D, Dileep V, Quivy JP, Foti R, Tili F, Santarella-Mellwig R, Antony C, Almouzni G, Gilbert DM, Buonomo SBC. 2012. Mouse Rif1 is a key regulator of the replicationtiming programme in mammalian cells. EMBO J 31:3678-3690. doi: $10.1038 / \mathrm{emboj} .2012 .214$

Davé A, Cooley C, Garg M, Bianchi A. 2014. Protein Phosphatase 1 Recruitment by Rif1 Regulates DNA Replication Origin Firing by Counteracting DDK Activity. Cell Rep 7:53-61. doi:10.1016/j.celrep.2014.02.019

Dileep V, Rivera-Mulia JC, Sima J, Gilbert DM. 2015. Large-Scale Chromatin StructureFunction Relationships during the Cell Cycle and Development: Insights from Replication Timing. Cold Spring Harb Symp Quant Biol 80:53-63. 
doi:10.1101/sqb.2015.80.027284

Foti R, Gnan S, Cornacchia D, Dileep V, Bulut-Karslioglu A, Diehl S, Buness A, Klein FA, Huber W, Johnstone E, Loos R, Bertone P, Gilbert DM, Manke T, Jenuwein T, Buonomo SC. 2016. Nuclear Architecture Organized by Rif1 Underpins the ReplicationTiming Program. Mol Cell 61:260-273. doi:10.1016/j.molcel.2015.12.001

Fragkos M, Ganier O, Coulombe P, Méchali M. 2015. DNA replication origin activation in space and time. Nat Rev Mol Cell Biol 16:360-74. doi:10.1038/nrm4002

Gaboriaud J, Wu PYJ. 2019. Insights into the link between the organization of DNA replication and the mutational landscape. Genes (Basel). doi:10.3390/genes10040252

Gaggioli V, Le Viet B, Germe T, Hyrien O. 2013. DNA topoisomerase IIalpha controls replication origin cluster licensing and firing time in Xenopus egg extracts. Nucleic Acids Res 41:7313-7331. doi:10.1093/nar/gkt494

Gnan S, Flyamer IM, Klein KN, Castelli E, Rapp A, Maiser A, Chen N, Weber P, Enervald E, Cardoso MC, Bickmore WA, Gilbert DM, Buonomo SCB. 2021. Nuclear organisation and replication timing are coupled through RIF1-PP1 interaction. Nat Commun 12:1-10. doi:10.1038/s41467-021-22899-2

Hayano M, Kanoh Y, Matsumoto S, Renard-Guillet C, Shirahige K, Masai H. 2012. Rif1 is a global regulator of timing of replication origin firing in fission yeast. Genes Dev 26:137150. doi:10.1101/gad.178491.111

Herrick J, Stanislawski P, Hyrien O, Bensimon A. 2000. Replication fork density increases during DNA synthesis in X. laevis egg extracts. J Mol Biol 300:1133-1142. doi:10.1006/jmbi.2000.3930

Hiraga SI, Alvino GM, Chang FJ, Lian HY, Sridhar A, Kubota T, Brewer BJ, Weinreich M, Raghuraman MK, Donaldson AD. 2014. Rif1 controls DNA replication by directing Protein Phosphatase 1 to reverse Cdc7- mediated phosphorylation of the MCM complex. Genes Dev 28:372-383. doi:10.1101/gad.231258.113

Hiratani I, Gilbert DM. 2009. Replication timing as an epigenetic mark. Epigenetics 4:93-7.

Hiratani I, Ryba T, Itoh M, Rathjen J, Kulik M, Papp B, Fussner E, Bazett-Jones DP, Plath K, Dalton S, Rathjen PD, Gilbert DM. 2010. Genome-wide dynamics of replication timing revealed by in vitro models of mouse embryogenesis. Genome Res 20:155-169. doi:10.1101/gr.099796.109

Huang J, Wu S, Barrera J, Matthews K, Pan D. 2005. The Hippo signaling pathway coordinately regulates cell proliferation and apoptosis by inactivating Yorkie, the Drosophila homolog of YAP. Cell 122:421-434. doi:10.1016/j.cell.2005.06.007

Hyrien O, Maric C, Méchali M. 1995. Transition in specification of embryonic metazoan DNA replication origins. Science (80- ) 270:994-997. doi:10.1126/science.270.5238.994

Koberna K, Ligasová A, Malínský J, Pliss A, Siegel AJ, Cvačková Z, Fidlerová H, Mašata M, Fialová M, Raška I, Berezney R. 2005. Electron microscopy of DNA replication in 3-D: Evidence for similar-sized replication foci throughout S-phase. J Cell Biochem 94:126138. doi:10.1002/jcb. 20300

Kumar R, Cheok CF. 2014. RIF1: A novel regulatory factor for DNA replication and DNA damage response signaling. DNA Repair (Amst) 15:54-59. doi:10.1016/J.DNAREP.2013.12.004

Kumar S, Yoo HY, Kumagai A, Shevchenko Anna, Shevchenko Andrej, Dunphy WG. 2012. Role for Rif1 in the checkpoint response to damaged DNA in Xenopus egg extracts. Cell Cycle 11:1183-1194. doi:10.4161/cc.11.6.19636

Labit H, Perewoska I, Germe T, Hyrien O, Marheineke K. 2008. DNA replication timing is deterministic at the level of chromosomal domains but stochastic at the level of replicons in Xenopus egg extracts. Nucleic Acids Res 36:5623-34. doi:10.1093/nar/gkn533

Lian I, Kim J, Okazawa H, Zhao J, Zhao B, Yu J, Chinnaiyan A, Israel M a, Goldstein LSB, 
Abujarour R, Ding S, Guan KL. 2010. The role of YAP transcription coactivator in regulating stem cell self-renewal and differentiation. Genes Dev 24:1106-1118. doi:10.1101/gad.1903310

Livak KJ, Schmittgen TD. 2001. Analysis of relative gene expression data using real-time quantitative PCR and the 2- $\Delta \Delta C$ T method. Methods 25:402-408. doi: 10.1006/meth.2001.1262

Machida YJ, Hamlin JL, Dutta A. 2005. Right place, right time, and only once: Replication initiation in metazoans. Cell. doi:10.1016/j.cell.2005.09.019

Marchal C, Sima J, Gilbert DM. 2019. Control of DNA replication timing in the 3D genome. Nat Rev Mol Cell Biol 20:721-737. doi:10.1038/s41580-019-0162-y

Marheineke K, Goldar A, Krude T, Hyrien O. 2009. Use of DNA combing to study DNA replication in Xenopus and human cell-free systems. Methods Mol Biol 521:575-603. doi:10.1007/978-1-60327-815-7_33

Marheineke K, Hyrien O. 2004. Control of replication origin density and firing time in Xenopus egg extracts. Role of a caffeine-sensitive, ATR-dependent checkpoint. J Biol Chem 279:28071-28081. doi:10.1074/jbc.M401574200

Marheineke K, Hyrien O. 2001. Aphidicolin triggers a block to replication origin firing in Xenopus egg extracts. J Biol Chem 276:17092-17100. doi:10.1074/jbc.M100271200

Matthews G, Colman A. 1991. A highly efficient, cell-free translation/translocation system prepared from Xenopus eggs, Nucleic Acids Research.

Moris N, Pina C, Arias AM. 2016. Transition states and cell fate decisions in epigenetic landscapes. Nat Rev Genet 20161711 17:693-703. doi:10.1038/nrg.2016.98

Newport J, Kirschner M. 1982. A major developmental transition in early xenopus embryos: II. control of the onset of transcription. Cell 30:687-696. doi:10.1016/00928674(82)90273-2

Nieuwkoop PD (Pieter D., Faber J. 1994. Normal table of Xenopus laevis (Daudin) : a systematical and chronological survey of the development from the fertilized egg till the end of metamorphosis. Garland Pub.

Parker MW, Bell M, Mir M, Kao JA, Darzacq X, Botchan MR, Berger JM. 2019. A new class of disordered elements controls DNA replication through initiator self-assembly. Elife 8. doi: $10.7554 /$ eLife.48562

Pefani D-E, Latusek R, Pires I, Grawenda AM, Yee KS, Hamilton G, Weyden L van der, Esashi F, Hammond EM, O’Neill E. 2014. RASSF1A-LATS1 signalling stabilises replication forks by restricting CDK2-mediated phosphorylation of BRCA2. Nat Cell Biol 16:962. doi:10.1038/NCB3035

Perez-Riverol Y, Csordas A, Bai J, Bernal-Llinares M, Hewapathirana S, Kundu DJ, Inuganti A, Griss J, Mayer G, Eisenacher M, Pérez E, Uszkoreit J, Pfeuffer J, Sachsenberg T, Yilmaz Ş, Tiwary S, Cox J, Audain E, Walzer M, Jarnuczak AF, Ternent T, Brazma A, Vizcaíno JA. 2019. The PRIDE database and related tools and resources in 2019: Improving support for quantification data. Nucleic Acids Res 47:D442-D450. doi:10.1093/nar/gky1106

Perron M, Kanekar S, Vetter ML, Harris WA. 1998. The Genetic Sequence of Retinal Development in the Ciliary Margin of theXenopusEye. Dev Biol 199:185-200. doi:10.1006/dbio.1998.8939

Prioleau MN, MacAlpine DM. 2016. DNA replication origins-Where do we begin? Genes Dev. doi:10.1101/gad.285114.116

Ramos A, Camargo FD. 2012. The Hippo signaling pathway and stem cell biology. Trends Cell Biol. doi:10.1016/j.tcb.2012.04.006

Räschle M, Knipscheer P, Knipsheer P, Enoiu M, Angelov T, Sun J, Griffith JD, Ellenberger TE, Schärer OD, Walter JC. 2008. Mechanism of replication-coupled DNA interstrand 
crosslink repair. Cell 134:969-80. doi:10.1016/j.cell.2008.08.030

Rippe K. 2021. Liquid-Liquid Phase Separation in Chromatin. Cold Spring Harb Perspect Biol a040683. doi:10.1101/cshperspect.a040683

Ryba T, Hiratani I, Lu J, Itoh M, Kulik M, Zhang J, Schulz TC, Robins AJ, Dalton S, Gilbert DM. 2010. Evolutionarily conserved replication timing profiles predict long-range chromatin interactions and distinguish closely related cell types. Genome Res 20:761770. doi:10.1101/gr.099655.109

Sajgo S, Ghinia MG, Brooks M, Kretschmer F, Chuang K, Hiriyanna S, Wu Z, Popescu O, Badea TC. 2017. Molecular codes for cell type specification in Brn3 retinal ganglion cells. Proc Natl Acad Sci U S A 114:E3974-E3983. doi:10.1073/pnas.1618551114

Sasaki T, Sawado T, Yamaguchi M, Shinomiya T. 1999. Specification of Regions of DNA Replication Initiation during Embryogenesis in the 65-Kilobase DNApol $\alpha$-dE2F Locus of Drosophila melanogaster. Mol Cell Biol 19:547-555. doi:10.1128/mcb.19.1.547

Schindelin J, Arganda-Carreras I, Frise E, Kaynig V, Longair M, Pietzsch T, Preibisch S, Rueden C, Saalfeld S, Schmid B, Tinevez JY, White DJ, Hartenstein V, Eliceiri K, Tomancak P, Cardona A. 2012. Fiji: An open-source platform for biological-image analysis. Nat Methods. doi:10.1038/nmeth.2019

Siefert JC, Georgescu C, Wren JD, Koren A, Sansam CL. 2017. DNA replication timing during development anticipates transcriptional programs and parallels enhancer activation. Genome Res 27:1406-1416. doi:10.1101/gr.218602.116

Sive HL, Grainger RM, Harland RM. 2007. Xenopus laevis In Vitro Fertilization and Natural Mating Methods. CSH Protoc 2007:pdb prot4737. doi:10.1101/pdb.prot4737

Totaro A, Panciera T, Piccolo S. 2018. YAP/TAZ upstream signals and downstream responses. Nat Cell Biol. doi:10.1038/s41556-018-0142-Z

Toyoshima H, Hunter T. 1994. p27, a novel inhibitor of G1 cyclin-Cdk protein kinase activity, is related to p21. Cell 78:67-74. doi:10.1016/0092-8674(94)90573-8

Van Dierendonck JH, Keyzer R, van De Velde CJH, Cornelisse CJ. 1989. Subdivision of Sphase by analysis of nuclear 5-bromodeoxyuridine staining patterns. Cytometry 10:143150. doi:10.1002/cyto. 990100205

Wang P, Bai Y, Song B, Wang Y, Liu D, Lai Y, Bi X, Yuan Z. 2011. PP1A-mediated dephosphorylation positively regulates YAP2 activity. PLoS One 6:e24288. doi:10.1371/journal.pone.0024288

Wang WL, Shechter D. 2016. Chromatin assembly and transcriptional cross-talk in Xenopus laevis oocyte and egg extracts. Int J Dev Biol 60:315-320. doi:10.1387/ijdb.160161ds

Weir E, McLinden G, Alfandari D, Cousin H. 2021. Trim-Away mediated knock down uncovers a new function for Lbh during gastrulation of Xenopus laevis. Dev Biol 470:74-83. doi:10.1016/j.ydbio.2020.10.014

Wolffe AP. 1993. Replication timing and Xenopus 5S RNA gene transcription in vitro. Dev Biol 157:224-231. doi:10.1006/dbio.1993.1126

Yamazaki S, Hayano M, Masai H. 2013. Replication timing regulation of eukaryotic replicons: Rif1 as a global regulator of replication timing. Trends Genet. doi:10.1016/j.tig.2013.05.001

Yamazaki S, Ishii A, Kanoh Y, Oda M, Nishito Y, Masai H. 2012. Rif1 regulates the replication timing domains on the human genome. EMBO J 31:3667-3677. doi:10.1038/emboj.2012.180

Yan F, Qian M, He Q, Zhu H, Yang B. 2020. The posttranslational modifications of HippoYAP pathway in cancer. Biochim Biophys acta Gen Subj 1864:129397. doi:10.1016/j.bbagen.2019.07.006

Zanconato F, Forcato M, Battilana G, Azzolin L, Quaranta E, Bodega B, Rosato A, Bicciato S, Cordenonsi M, Piccolo S. 2015. Genome-wide association between YAP/TAZ/TEAD 
and AP-1 at enhancers drives oncogenic growth. Nat Cell Biol 17:1218-1227. doi:10.1038/ncb3216

Zhao B, Li L, Lei Q, Guan KL. 2010. The Hippo-YAP pathway in organ size control and tumorigenesis: An updated version. Genes Dev. doi:10.1101/gad.1909210

Zhao B, Ye X, Yu Jindan, Li L, Li W, Li S, Yu Jianjun, Lin JD, Wang CY, Chinnaiyan AM, Lai ZC, Guan KL. 2008. TEAD mediates YAP-dependent gene induction and growth control. Genes Dev 22:1962-1971. doi:10.1101/gad.1664408 